Arguments, Adjuncts and Instruments in English and Turkish

by

\title{
Lara Russo
}

A thesis submitted to the Faculty of Graduate and Postdoctoral Affairs in partial fulfillment of the requirements for the degree of

Master

in

Cognitive Science

Carleton University

Ottawa, Ontario

(C) 2021

Lara Russo 


\begin{abstract}
The argument-adjunct distinction is highly discussed in the literature. There is an ongoing debate about the categorization of instruments. Some linguists classify them as arguments, some classify them as adjuncts, and some argue that they are arguments for some verbs and adjuncts for others. This thesis revisits the argument-adjunct distinction and investigates the categorization of instruments in English and Turkish using both traditional argumenthood tests and reaction time studies. Phrases with instrumental case (Turkish -(y)le) or preposition marking (English with) can be clear arguments or adjuncts, but instruments seem to fall in between in both languages. Some argumenthood tests classify instruments as arguments and some as adjuncts. The current thesis thus adds support to previous studies that have argued that English instrument phrases have unclear status as arguments or adjuncts. Furthermore, the studies presented here found no statistical difference in reaction time categories between arguments, adjuncts and instruments. This might be because the specific method used was not sensitive enough.
\end{abstract}




\section{Acknowledgment}

It would not have been possible to write this thesis without the help and support of the people around me. First, I would like to thank the willing participants and my dear friends who spread the research.

I would like to express my sincere appreciation and gratitude to my supervisor Dr. Ida Toivonen and the member of my thesis committee Dr. Kumiko Murasugi.

I was lucky enough to take my first linguistics class from my current supervisor Dr. Toivonen when I decided to change my major from Psychology to Linguistics. She has thought and inspired me since that first class. It did not take too long for her to become my mentor and role model. Ida has not just though me about arguments and adjuncts or designing psycholinguistic studies. She also influenced me with her immense knowledge, passion, patience and motivation.

Dr. Kumiko Murasugi's contributions are manyfold; her comments led to great improvements to the design of the study, and she hugely contributed to my statistical analysis.

I also would like to thank you, Dr. Karen Jesney, for kindly accepting being my internal committee member and changing my perspective by asking great questions.

Special thanks to Dr. Roxana Barbu (one of the reasons I am here) for teaching me the survival methods in graduate life. It was great luck for me to work with her before my graduate studies and learn for her.

Moreover, I would like to thank my dear colleagues and friends Taeko Bourque and Ashley Promislow. Unfortunately, we were not in the same city, we could not meet in person, but they were still always ready to help, celebrate successes, or simply talk through Zoom.

I want to extend my sincere gratitude to my friends who always Evin Sezer, Pelin and Eliz Zengin and Irem Bor, for the cheer and support you lent me over all my graduate life.

Cagla Eren Cimenci deserves double thanks, she is the definition of a good friend, and I know that she always has the best answers to all my questions about graduate life.

A very special thanks to thanks to Nazli, Emrah, Sarp and Alp Alpsan. They became my family during the hard times, and they always supported and motivated me.

Finally, I would like to thank my parents Estel and Marsel Russo, who always encouraged and helped me became who I am. I am grateful for their patience and sacrifice that will remain my inspiration throughout my life. I am also very much grateful to all my family members for their constant inspiration, confidence and love. I also would like to thank (a little unorthodox) my dogs Buck, Ciko and Sila for giving unconditional love and support. 


\section{Contents}

1 Introduction $\quad 1$

1.1 Brief introduction to the argument-adjunct distinction $\ldots \ldots \ldots \ldots \ldots$

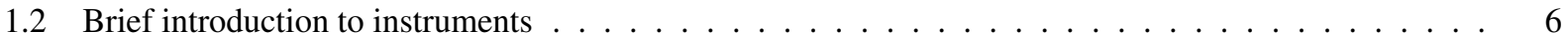

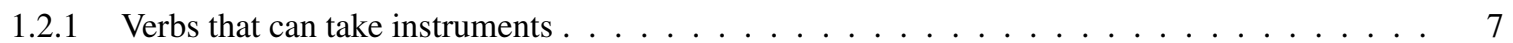

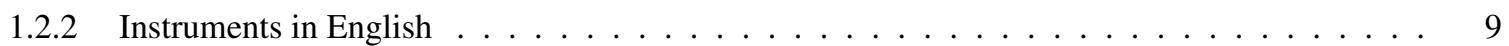



2 Argumenthood Tests $\quad 14$

2.1 Tests that can be used in Turkish $\ldots \ldots \ldots \ldots \ldots \ldots \ldots \ldots \ldots$

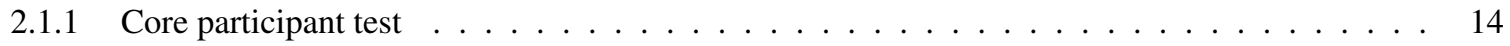

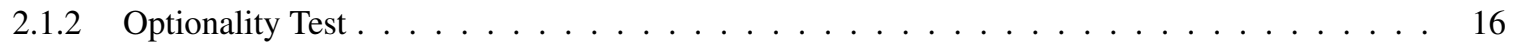

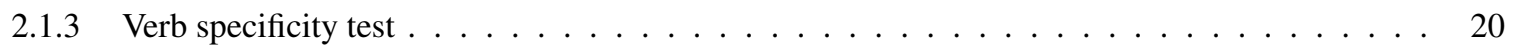

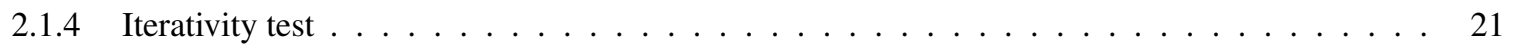

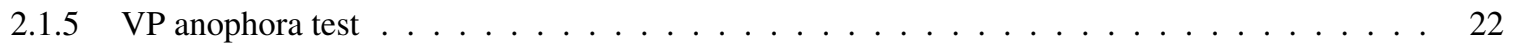

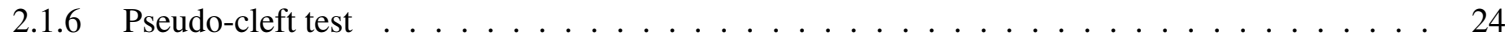

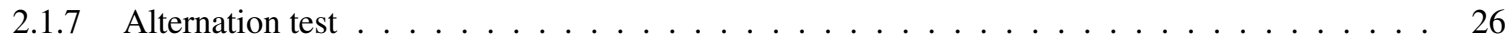

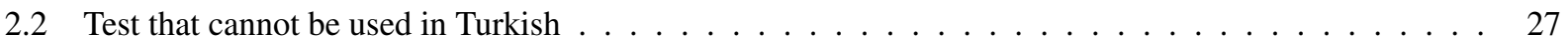

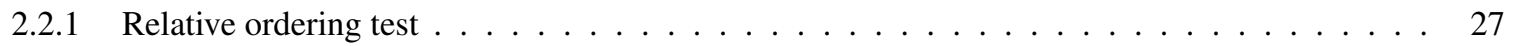

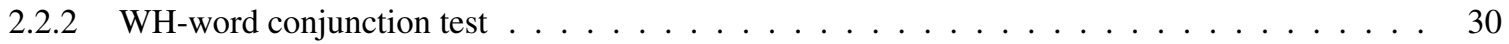

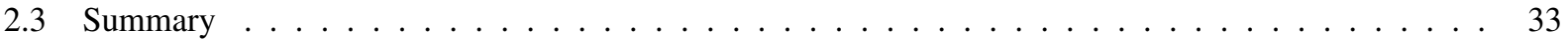

3 Study $\quad 33$

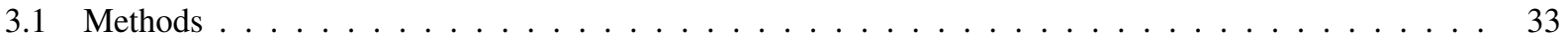

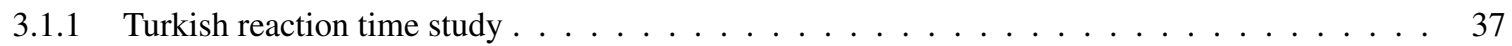

3.1 .2 English reaction time study $\ldots \ldots \ldots \ldots \ldots \ldots \ldots \ldots \ldots \ldots$

3.1.3 Stimulus Norming Study . . . . . . . . . . . . . . . . . . . . . . . . . . . . 41 


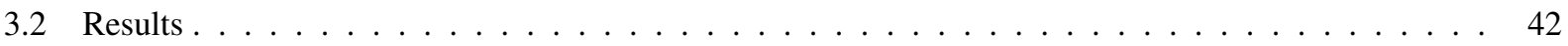

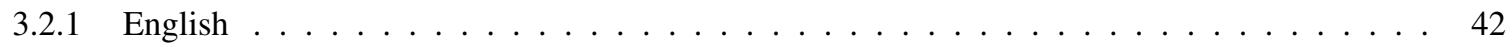

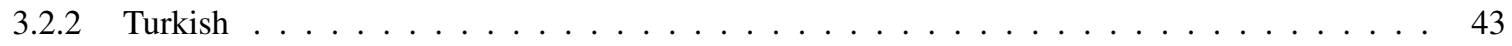

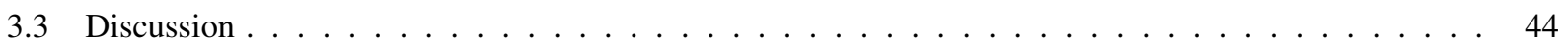

4 Conclusion $\quad 46$

$\begin{array}{ll}\text { Appendix } & 48\end{array}$

4.1 Appendix 1: English study $\ldots \ldots \ldots \ldots \ldots \ldots \ldots$

4.2 Appendix $2:$ Turkish study $\ldots \ldots \ldots \ldots \ldots \ldots \ldots \ldots \ldots \ldots$

$\begin{array}{lr}\text { References } & 64\end{array}$ 


\section{List of Abbreviation}

1PS First Person Singular

3PS Third Person Singular

ABL Ablative

ACC Accusative

ADJ Adjunct

ARG Argument

CAUS Causative

DAT Dative

GEN Genitive

LOC Locative

INS . Instrument

ObjP . Object Participle

SubjP Subject Participle

POSS

Possessive

PL . Plural 


\section{Introduction}

There is an ongoing debate in the literature on whether instrumental phrases should be categorized as arguments or as adjuncts. Some linguists classify them as arguments (Schütze 1995; Schütze and Gibson 1999; Tutunjian and Boland 2008 among others), some classify them as adjuncts (Spivey, Tanenhaus, Eberhard and Sedivy 2002;Spivey-Knowlton and Sedivy 1995 among others) and some others argue that they are arguments for some verbs and adjuncts for others (Rissman 2013).

In this thesis, I focused on two languages (English and Turkish) and I used two methods to investigate whether instruments pattern with arguments or adjuncts.

1) argumenthood tests

2) a reaction time study

Before examining instruments, I investigated clear arguments and adjuncts with the instrumental preposition with in English and instrumental case marking -yle in Turkish.

First, I discuss the argument-adjunct distinction (section 1.1). This distinction is highly important in theoretical linguistics and psycholinguists. Then I explain instruments based on the literature in section 1.2.

\subsection{Brief introduction to the argument-adjunct distinction}

Most utterances in natural language describe situations. The addressees are supposed to immediately determine the situations explained in the utterances. To complete this task, they must use their language's lexicon and grammar. Linguists, pyscholinguists, and computational linguists are aiming to determine the contribution of different techniques to the process of understanding an utterance. In doing so, analyzing the different parts of sentences in relation to the verb is the most common way (Koenig et al. 2003). For example, in (1a), there are several participants that are specified in relation to the 'giving' event. The participants that are involved in that event are 'Aura', 'yellow dress' and 'to Mary'. On the other hand, 'last summer' and 'at the beach' are not asked by the 'giving' event (Barbu 2020).

(1) a. Aura gave a yellow dress to Mary last summer at the beach

b. She ate a sandwich for lunch.

c. Chris recommended a movie to Kim in the hallway.

The contrast between the boldfaced and the underlined phrases in (1a) illustrate the argument-adjunct distinction. As a 'giving' event requires a 'giver', something to give and a receiver, those are the core participants in that sentence and they are referred to as arguments. The rest are optional and they are referred to as adjuncts.

In a very short explanation, a word or phrase is classified as an argument if it expresses information necessary for the verb meaning (e.g., she, a sandwich in (1b)). Otherwise, the word or phrase is an adjunct (e.g., for lunch in (1b)). 
The notion of argumenthood and the argument-adjunct distinction are not always easy to define but are crucial to linguistics. According to their very basic explanations arguments and adjuncts have two major differences: 1) arguments are syntactically obligatory and adjuncts are not, 2) arguments are semantically core to the activity or state denoted by the verb. In other words, if a word or phrase expresses necessary information for the verb meaning (e.g. Chris, a movie, and to Kim in (1c)), that word or phrase is syntactically obligatory, semantically core and considered as an argument. Otherwise, it is an adjunct (e.g. in the hallway in (1c)). For example in sentence (1c) Chris recommended implies that Chris recommended something to someone but that does not imply a location (Boland, 2005).

In theoretical linguistics, many syntactic theories - such as Principles and Parameters (Chomsky 1981), LexicalFunctional Grammar (Kaplan and Brensan 1982), and Role and References Grammar (Van Valin and LaPolla 1997) make a distinction between arguments and adjuncts.

\section{Argument Structure}

As mentioned earlier, arguments and adjuncts are defined in relation to the verb. The same participant might be an argument in one sentence but adjunct in another one depending on the verb of the sentence. There are different verbs that can take different numbers of arguments and that is called verb argument structure. Verbs can take up to four arguments, however, there is no limits for adjuncts (Tesnière 1959, Kearns 2011, Traxler 2011). Verbs that can take only one argument are called intransitive verbs. Verbs that can take two arguments are called transitive verbs and the verbs that can take more than two arguments are called ditransitive verbs.

\section{Intransitive verbs}

Intransitive verbs only take an external argument (subject). In other words, they require a single NP subject (Carnie 2016).

(2) a. Marc arrived late last night.

b. * arrived late last night.

Arriving takes one semantic argument. It only requires an external argument (a subject). It is expressed as 'Marc' in (2a). On the other hand, (2b) is ungrammatical because it does not have a subject. In (2), late last night is an adjunct. It provides additional information about the time of arriving. Some other intransitive verbs include: sleep, laugh, smile, sneeze, die, and fall. 


\section{Transitive verbs}

Transitive verbs take two arguments, one external argument (subject) and one internal argument. In other words, they require an NP subject and an NP, PP or CP object (Carnie 2016).

The verb hit is an example of a transitive verb, as shown in the example below:

(3) a. Celine hit the ball in the morning.

b. * Celine hit in the morning.

c. * hit the ball in the morning.

The verb hit takes two semantic arguments: the person who hits, in (3a) it is expressed by Celine; and the thing being hit, in (3a) it is expressed by the ball. On the other hand, in the morning is an adjunct for the hitting event and expresses the time of that event. (3b) is ungrammatical because there the required internal argument is dropped. Similarly, the example is ungrammatical when the external argument is dropped in (3c). Some other transitive verbs are kiss, love, smoke, and hug.

\section{Ditransitive verbs}

Ditransitive verbs take two internal arguments, they take three arguments including the subject (Tesnière 1995, Kearns 2011, Traxler 2011).

According to Carnie (2016), there are several types of ditransitive verbs: 1) Some of them requires an NP as an external argument (subject) and two NPs as internal arguments (the first one as an indirect object and the second one as a direct object), however, they do not allow PP arguments (4). 2) Some ditransitive verbs requires an NP external argument and they require an NP and a PP internal arguments (5). 3) The third type of ditransitive verbs are combination of the first two type, an NP or a PP can appear as the second internal argument (6). 4) The last type of ditransitive verbs can take an NP, a PP or a $\mathrm{CP}$ as the second internal argument (7).

\section{(4) I spared him the trouble.}

The sparing event requires three arguments. There is an external argument NP which is expressed by $I$, and two internal NP arguments expressed by him and the trouble, in (4).

\section{(5) I put the book in the box.}

The putting event requires three arguments, one external and two internal arguments. There is an external NP argument, in (5), it is expressed by $I$, and there are two internal arguments, one NP argument expressed by the book and one PP argument expressed by in the box.

(6) a. I gave the book to Leah.

b. I gave Leah the book. 
The giving event requires three arguments, one external and two internal arguments. There is one external NP argument, in (6) it is expressed by $I$. There are two internal arguments, in (6a), there is one internal NP argument, expressed by the book and an internal PP argument expressed by to Leah. On the other hand, in (6b) there are two internal NP arguments expressed by Leah and the book.

\section{(7) a. I told Daniel the story. \\ b. I told Daniel the exam was cancelled. \\ c. I told the story to Daniel.}

The telling event required three arguments as well. There is one external and two internal arguments. In (7) the external NP is expressed by $I$. All three sentences above have an NP as the first internal argument. In (7a) and (7b) the first internal NP is expressed by Daniel, and in (7c) it is expressed by the story. On the other hand, the second syntactic properties of the second argument are different. In (7a), there is an NP as the second internal argument and it is expressed by the story. In (7b), there is a $\mathrm{CP}$ as a second internal argument and it is expressed by the exam was cancelled. Lastly, in (7c), there is a PP as a second internal argument and it is expressed by to Daniel.

\section{The difference between semantic and syntactic arguments}

It is important to clarify the concepts of semantic arguments, syntactic arguments and argument structure to see the complexity of the distinction between them. For any given verb, there is a number of participants, except for the intransitive verbs with dummy subjects (such as rain, snow, etc.) as demonstrated in (8).

(8) It rains.

The dummy subjects in this case are syntactically obligatory but they do not semantically correspond to the participant doing the event, such as it in (8) (Barbu 2020).

Participants may refer to both animate and inanimate entities in order for the event or situation described by the verb to take place. Let's consider the verbs to devour, to eat and to swallow discussed by Jackendoff (2002).

The semantic arguments for the verb to devour are the things that a devouring event or situation can take place with. Which means, according to Jackendoff (2002), two participants are required: 1) the thing doing the devouring, and 2) the thing being devoured as demonstrated in (9).

(9) a. Susie devoured a pizza.

b. * Susie devoured. 
In (9a), the verb to devour has two arguments, Susie and a pizza, and the sentence is complete and grammatically correct. On the other hand, in (9b) the argument a pizza is omitted and the sentence is ungrammatical. Considering this example, it is possible to conclude that in case of the verb to devour both semantic arguments need to be expressed. This means that they are both semantic and syntactic arguments. In other words, those arguments are semantically and syntactically obligatory.

Now, consider the verb to eat, which is almost synonymous with the verb to devour. The verb to eat also requires two semantic arguments, similar to the verb to devour. The two required participants are: 1) the thing doing the eating, and 2) the thing being eaten (Jackendoff, 2002).
(10) a. Susie ate a pizza.
b. Susie ate.

In the case of the verb to eat, it is possible to drop the internal argument as seen in (10b). (10a) contains both of the syntactic arguments: Susie and the pizza. This sentence is complete and grammatical in English. On the other hand, in (10b) one of the required participants, a pizza is absent, however, the sentence is still grammatical. The example sentences (10) show that the thing being eaten is an optional syntactic argument of the verb to eat. In other words, in this case the internal argument is semantically obligatory but syntactically optional.

A third example verb is to swallow, as in (11).
(11) a. Susie swallowed a seed.
b. Susie swallowed.

This case is a little different than the verb to devour and the verb to eat.

As noted by Jackendoff (2002), the verb to swallow has two usages with different semantic and syntactic requirements. First, the verb can be used as seen in (11a). It requires two semantic arguments: 1) the thing doing the swallowing and 2) the thing being swallowed (Jackendoff, 2002). On the other hand, it is also possible to swallow without swallowing something (11b) requires only one semantic argument, the thing doing the swallowing. In this case, the verb to swallow only needs one semantic argument. In other words, it is possible to conclude that the internal argument (the thing being swallowed) is an optional semantic argument of the verb to swallow.

To summarize, semantic arguments refer to the participants that are required by the verb and which are essential for the meaning of the verb. Semantic arguments can be obligatory as exemplified with the verb to devour and the verb to eat, or it can also be optional, as it is exemplified with the verb to swallow. Likewise, syntactic arguments can either be obligatory as exemplified with the verb to devour or optional as exemplified with the verbs to eat and to swallow. Understanding whether an argument is syntactic or semantic or both and their obligatoriness is crucial to understanding the verb's argument structure. 


\section{Optional arguments}

As mentioned above, with a very basic explanation, arguments are semantically and syntactically obligatory to the verb. However, some arguments can be dropped in some cases, as illustrated in section Difference between Semantic and Syntactic Arguments. It is possible to omit the required semantic argument for the verb to eat shown in (10b). However, not all verbs allow speakers to omit a required semantic argument, for example, the verb to devour does not allow it, shown in (9b) (Jackendoff, 2002).

\section{Obligatory adjuncts}

In the literature, adjuncts are defined as optional. However, in some cases they cannot be dropped. For example, the by phrases are adjuncts that complete the passive sentences. For some passive sentences, they are optional (12) (Grimsaw and Vikner, 1993).

(12) a. The conversation was recorded.

b. The lecture was transcribed.

However, the passive by phrases might also be obligatory for some other sentences. The sentences (13a and 13c) are incomplete or ungrammatical in English. On the other hand, when the by phrase is not missing, (13b and 13d) the sentences are complete and grammatical (Grimsaw and Vikner, 1993).
(13) a. * Danger was sensed.
b. Danger was sensed by John.
c. * Harry was feared.
d. Harry was feared by John.

(Jackendoff 1977, pp.92)

\subsection{Brief introduction to instruments}

In the literature, there is an ongoing debate on whether instrumental phrases are best categorized as arguments or adjuncts. Instruments have been studied extensively; however it is not clear whether instruments pattern with arguments or with adjuncts (Rissman and Rawlins 2017). The unclear argumenthood status of instruments makes it potentially relevant for arriving at a better understanding of the argument-adjunct distinction.

Instruments are hard to categorize as argument or adjunct using classical argumenthood tests. Some argumenthood tests categorizes instruments as arguments (Verb Specificity Test, Alternation Test), some categorize them as adjuncts (Optionality Test, Pseudo-cleft Test) and some other tests are inconclusive and lead to mixed results (Core Participant Test, Iterativity Test). I explain those tests in detail in section 2. 


\subsubsection{Verbs that can take instruments}

Verbs that occur with instruments can be divided into two classes: allow verbs and require verbs (Koenig et al. 2003, Rissman et al. 2015).

Require verbs are the verbs where the instrumental with-phrase completes the meaning of the verb. Some examples are slice, write and cut. In other words, they require an instrument to be a complete meaning of the verb (Rissman and Rawlins 2017; Rissman 2011).
(14) a. Marc wrote the exam with his favorite pen.
b. Alice cut the paper with scissors.

The verb write in (14a) and cut in (14b) are examples of require verbs. the instrumental phrases with his favorite pen and with scissors complete the verb. In other words, one could not perform those actions without an instrument. They may or may not be overtly pronounced; however, they always conceptually exist.

Allow verbs are the verbs that can take instrumental with-phrase but they do not require them. Some examples are: eat, calculate and clean (Rissman 2015; Rissman 2013).

\section{(15) a. Sue calculated the taxes with a calculator. \\ b. John cleaned the kitchen with an electrical broom.}

In (15), two allow-sentences are shown. The verbs calculate (15a) and clean are allow verbs. They can take the instrumental phrases with a calculator and with an electrical broom, but instrumental phrases are not necessary in order for the event to take place. In this case, the instrumental phrases provide additional information that are not required by the verb.

According to Barbu (2020), there are only a handful of studies that investigates the distinction between allow and require verbs. This distinction was first proposed by Koenig et al. (2003). They have asked two informants the question showed in (16) for 4200 verbs. They concluded that there are two groups of instrument verbs. According to their informants, for verbs such as write, slice, and beat one participant should use another participant to perform the action. In their study, they used the term participant to indicate the constituents. On the other hand, for the verbs such as eat, open and kill, they have judged that instruments can be used but are not necessary.

(16) Does one of verb's senses describe situations in which one participant must, can, or cannot use another participant to perform an action? 
Koenig et al. (2003) also found that sentences that include an instrumental phrase were read faster if the verb is a require verb rather than an allow verb. That difference in reading times provide evidence for two distinct classes of instrument verbs. Rissman et al. (2015) conducted three experiments on this distinction. They used the verbs that Koenig et al. (2003) categorized as require- and allow-instruments and their goal was to examine whether instruments are more likely to be categorized as arguments if they are require-instruments rather than allow-instruments.

In the first two experiments, they instructed the participants on the notion of argument and the speakers were asked which of the phrases in brackets are arguments. They were presented with sentences like in (17).

(17) a. Martha chopped something [with a bread knife] [in the operating room].

b. John served something [to the musicians][gracefully].

c. Chris drew something [passionately] [at school].

d. Jim carried [the books] [in a tote bag].

They had stimuli that contrasted instruments and adjuncts (17a), recipients (clear arguments) and adjuncts (17b), adjuncts and adjuncts (17c). To understand the effectiveness of the study, they have also included sentences contrasting recipients and adjuncts $(17 \mathrm{~d})$.

The participants were asked to identify the arguments (if any) of the sentences considering the phrases in brackets. For example, they would mark [to the musicians] as an argument and [gracefully] as an adjunct, in (17b). In (17c), they would not mark either [passionately] or [at school] as arguments.

In the control sentences - the sentences that compare a direct object and an adjunct - 97\% of the participants selected the direct object as an argument. This showed that the instructions were effective in distinguishing uncontroversial arguments from adjuncts.

In their second study, the participants received the same training. However, they did not see sentences in this study. Instead, they were asked to give possible arguments to the specific verbs as in (18).

What is/are the argument(s) of chop?

Participants typed their answers in a box on a computer screen. There was no time limit for this experiment. The speakers were less likely to mention instruments as an argument in the second study than the first study.

In the third experiment, the participants did not receive a training on arguments. They were presented with the same sentences as in the first study, and they were asked to consider the meaning of all the bracketed phrases and determine the most important in the sentences. According to the results, participants were more likely to consider instruments important than they were to select them as arguments in the first experiment. 
In the first two experiments, where the participants were trained, there was a support for the allow/require distinction. The participants were more likely to mark require-instrument verbs as having arguments than allow-instrument verbs. In contrast, the third study did not show a significant difference between allow/require verbs. They marked instruments as important regardless of the category of the verb.

In her dissertation, Barbu (2020) conducted a cross-linguistic study in four languages (English, Romanian, Turkish and Spanish). She designed a study to investigate speakers' semantic intuition. They were instructed to imagine an empty box and they were asked to write the necessary participants for the event to occur. The participants were instructed to write down all the participants that must be in the box in order for the event to occur. The results showed that there are more mentions of instruments for require verbs than allow verbs in all languages. This study is explained more in detail in section 2.1.1.

In short, both groups of verbs can take instruments, it is not syntactically ungrammatical to add an instrumental phrase to sentences with either of the verb classes. However, it is not possible to do the action without an instrument in require-sentences, on the other hand it is possible for the action to happen without instrumental phrases in allowsentences. The instrumental phrase might be silent in the sentences with require-verbs as well, but as a speaker or listener, we are aware that an instrument is semantically required.

\subsubsection{Instruments in English}

English instrumental phrases can be constructed in several ways. The more frequent ways are with-instruments and use-instruments. This section will introduce both ways, however, this thesis mostly focused on with-instruments.

Instrumental phrases can have several roles according to some previous research. This property of instruments is not specific to English (as explained in 1.2.3), however this section will focus on English.

According to Croft (1991) instrumentals can have causal meaning as seen in (19). The instrumental phrase "with a knife', in this sentence has a causal sense, i.e. the subject (Margie) causes the knife to slice the bread. Croft (1991) argues that this kind of instrumental phrase has the instrument as "intermediate in a causal chain between the subject (initiator) and the direct object (final affected entity)".

Margie sliced the bread with a knife.

In (19), the knife is a causal intermediary, as Margie (the subject) causes it to do the slicing action.

Schlesinger (1995) and Koenig et al. (2008) mention that instruments can play different roles in different events. They can have a causal relationship like in (19). However, not all instruments have the same causal relation with the action. They might play a facilitating or helping role. Both with-instruments and use-instruments might have that role as in (20). 
(20) a. Sue drank her coca with a straw.

b. Chloe used a ladder to paint the ceiling.

(Rissman 2011, p. 534)

In (20a), the instrumental phrase with a straw does not cause the drinking action. However it facilitates it. Likewise, in (20b) the ladder does not cause the painting event, it is the facilitator in this sentence.

The instrumental role is not totally determined by the meaning of the verb; there are also different kinds of instrumental phrases which may affect their meaning. In English, there are two main kinds of instrumental phrases, use instrumental phrases as seen in (21a) and with instrumental phrases as seen in (21b) (Rissman 2011).

(21) a. Cinderella used an old toothbrush to scrub the floor.

b. Cinderella scrubbed the floor with an old toothbrush.

(Rissman 2011, p.532)

According to Fillmore (1968), instrumental phrases can have different roles in different structural positions. For example in (22), the instrumental phrase is exemplified as a subject and an object.

(22) a. The key opened the door.

b. John used the key to open the door.

(Rissman 2013, p.8)

In (22a), the instrumental phrase the key is the subject of the sentence. On the other hand, in (22b) it used as the object. According to Koenig et al. (2008), the role of use-instrument and the with-instrument are very similar, if not identical. On the other hand, Rissman (2013) argues that they are not exactly the same. For example, in the sentences (23) and (24) with-instrumental phrase and use-instrumental phrase cannot be used interchangeably.

(23) a. Nancy tripped and accidentally cut her dress with the scissors.

b. * Nancy tripped and accidentally used the scissors to cut her dress.

(Rissman 2013, p.8)

(24) a. Martha used scuba gear to clean the floor tank.

b. \# Martha cleaned the floor of the tank with scuba gear.

(Rissman 2013, p.8) 
In (25a) the with instrumental phrase shows that the cane is involved in the walking event but it also facilitates the event. On the other hand, in (25b), the instrumental phrase a cane has a causal relation with the walking event.
(25) a. Larry walks with a cane.
b. $\quad$ Larry used a cane to walk.

There are also psycholinguistic studies, especially eye tracking and reading time studies, on instruments. For example, Boland (2005) conducted an eye-tracking study to investigate which category instruments fell under. However, the results of the studies were unexpected. Instruments did not fall under either categories. They fell between arguments and adjuncts. Boland (2005) shows that instruments get more looks (more fixation) than locations (clear adjuncts) and less looks than recipients (clear arguments). They conclude that these results make instruments not typical argument or adjunct.

Also, Koenig et al. (2003) tested the distinction between arguments and adjuncts in a reading time experiment. Their results show that the instrumental phrases of most action verbs are read slower than state verbs. In other words, action verbs do not take instruments as arguments. However, according to Tutunjian and Boland (2005) a small subset of action verbs do.

In sum, the results from previous reaction time studies on the argumenthood of instruments are not completely consistent. Some researchers found that participants require a very short time to identify agents, a little longer for patients and goals. However, they take considerably longer time to identify instruments (Wilson, Papafragou and Trueswell 2011). According to Boland (2005), both instruments and and locations take longer to identify, so they are both adjuncts. Rissman (2011) argues that the with-instrumental phrases on required verbs are read faster in a psycholinguistic study than with-instrumental phrases of allow verbs. It is possible to describe the with-instrumental phrases of required verbs as more argument like than the ones of allow verbs as arguments are read faster than adjuncts (Rissman, 2011).

\section{Instrumental preposition with}

In English, one way of expressing instruments is by using the with preposition. There are other ways of expressing it as discussed above; however, for my purposes I will only focus on with-instruments.

This preposition is not specific to instruments as they can also be used to mark clear arguments and clear adjuncts, as seen in (26).

(26) a. Mark discussed the problem with his friend.

b. Jasmine cleaned her room with joy. 
In (26a) the with-phrase 'with his friend' is an argument as it is asked by the verb and it is semantically necessary, even if it might or might not be syntactically overt in the sentence. On the other hand in (26b) the with-phrase 'with joy' is an adjunct as it is an additional information, it is not semantically required and can be omitted..

\subsubsection{Instruments in Turkish}

In Turkish, we use the case marking $-(y) l e$, which is the abbreviated version of the postposition ile 'with', to mark instrumental phrases. It is also possible to mark them with the verb kullanmak 'to use'. In other words, we have the same two types of instruments as in English, as seen in (27). In (27a) the instrumental phrase is marked with the case marking -(y)le while in (27b) it is marked with kullanmak.

(27) a. Külkedisi yerleri eski bir dişfirçasıyla ov-du.

Cinderella floor old one toothbrush-INS scrub-PAST

'Cinderella scrubbed the floor with an old toothbrush.'

b. Külkedisi yerleri eski bir dişfirçası kullanarak ov-du.

Cinderella floor old one toothbrush use scrub-PAST

'Cinderella used an old toothbrush to scrub the floor.'

Instrumental phrases can be a subject or an object in Turkish as well as in English. For example in (28a) the instrumental phrase is in the subject position. On the other hand, in (28b) and in (28c) the instrumental phrase are considered object, as they are in the object position. Even if Turkish have a more flexible word order than English, the most frequent word order used in transitive sentences in Turkish is SOV with 48\% (Hoffman 1995). However, even if the sentence (28b) is grammatical, it is less often used than (28a) in Turkish.

(28) a. Bilgisayar hesap yaptı.

Computer calculate make-PAST

'The computer calculated.'

b. Can bilgisayarla hesap yaptı.

Can computer-INS calculate make-PAST

'Can calculated with a computer.'

c. ? Can hesabi bilgisayar kullanarak yaptı.

Can calculation-ACC computer use make-PAST

'Can used a computer to calculate.' 
As explained above for English instruments, instrumental phrases have different roles in Turkish as well. For example in (29a), the with instrumental phrase shows that the cane is involved in the walking event but it does also facilitates the event.
a. Leri baston-la yürü-dü.
Larry cane-INS walk-PAST
'Larry walks with a cane.'
b. Kemal merdiven kullanarak tavanı boyadı.
Kemal ladder use ceiling-ACC paint-PAST
'Kemal used ladder to paint the ceiling.'
c. Meri ekmeği bıçakla dilimledi.
Meri bread-ACC knife-INS slice-PAST
'Mery sliced the bread with a knife.'

In Turkish, the instrumental phrases can have a causal relationship like in (29c), in this case biçak 'knife' is the causal intermediary as Meri used it to do the action. On the other hand, they can also play a facilitator or helper role in Turkish similar to English. For example in (??), the instrumental phrases have a helping role. In (29a), the instrumental phrase bastonla 'with a cane' does not cause the action, but it facilitates it. Similarly, in (29b) merdiven 'ladder' facilitates the event of painting but it does not cause the action to happen.

Instruments are hard to categorize as arguments or adjuncts in Turkish as in English. As explained in section 2, the argumenthood tests lead to mixed results. For example, the tests such as Verb Specificity and Alternation tests categorize them as arguments, while tests such as Optionality and Pseudo-cleft tests categorize them as adjuncts. Some other tests such as Core Participant and Iterativity are inconclusive.

\section{Instrumental case marking $-y l e$}

As explained above, in Turkish, the most common way of expressing instruments is using the case marking - $(y) l e$, which is the shortened version of the preposition ile 'with'.

This case marking is not only used to specify instruments. It can also be used for argument prepositional phrases (30a) and adjunct prepositional phrases (30b). There are not too many instrumental case arguments; however, there are numerous instrumental case adjuncts.

(30) a. Tekin arkadaşılala tartıştı.

Tekin friend-POSS-INS discuss-PAST

'Tekin discussed with his friend.'

b. Seçil odasını büyük dikkatle temizledi.

Seçil room-POSS attention-INS clean-PAST

'Secil cleaned her room carefully.' 
In (30a), the phrase that takes instrumental case marking arkadaşıla 'with his friend' is a clear argument in this sentence. On the other hand in (30b), the phrase with instrumental case marking dikkatle 'carefully' is a clear adjunct.

In other words, in Turkish, the instrumental case marking is not specific for either arguments or adjuncts. They can be used for both, which means it is not possible to classify instruments as arguments or adjuncts simply by checking their case markings.

\section{Argumenthood Tests}

In this section I review some argumenthood tests that have been previously proposed for English. I specifically consider whether these tests can also be applied to Turkish. Then I apply them to instruments in Turkish and English and try to categorize them either as an argument or adjunct. Some of the tests that I discuss in this section categorize instruments as arguments and some categorize them as adjuncts.

\subsection{Tests that can be used in Turkish}

\subsubsection{Core participant test}

As discussed earlier, the very fundamental difference between arguments and adjuncts is that arguments are the core participants of an event while adjuncts are not. In other words, arguments are "the participants minimally involved in the activity or state expressed by the predicate" (Haegeman 1994, p.94) while adjuncts are peripheral participants (Geeraerts and Cuyckens 2007, p. 775)

This test relies on the intuitions of native speakers to decide whether some element of the sentence is a core participant or not. This intuition of whether a participant is conceptually necessary is very basic, but it is not always useful.

If we compare an eating event and a sleeping event, they require different numbers of core participants. In other words, they have different numbers of arguments. An eating event requires two core participants, someone to eat (Susie) and something to be eaten (a pizza) as seen in (31) while a sleeping event needs only one core participant, someone that sleeps (Mark) as seen in (32) (Needham and Toivonen, 2011).

(31) Susie ate a pizza.

(32) Mark sleeps. 
Similarly, in Turkish, different verbs require different number of core participants. For example, a yeme 'eating' event and a uyuma 'sleeping' event have different numbers of core participants in Turkish as well.

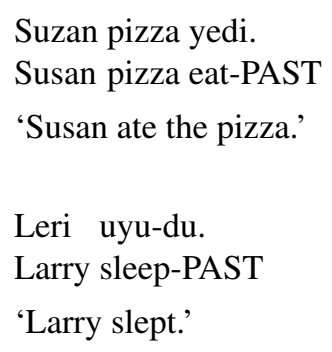

The yeme 'eating' event requires two core participants, something to eat (pizza) and someone whoe eats (Suzan) as in (33). On the other hand, the uyuma 'sleeping' event requires only one core participant, a sleeper (Leri) as exemplified in (34). This test works in Turkish in the same way that it works in English.

\section{Core Participant Test applied to Instruments}

According to this test, instrumental phrases are arguments if a verb needs the instrumental phrase to complete its meaning. On the other hand, if verbs do not need them to be semantically complete, instrumental phrases are adjuncts. For example, in a cutting event (require verb) the instrumental phrase with the scissors completes its meaning semantically, as seen in (35). On the other hand, in a watching event (allow verb), the instrumental phrase with binoculars is not semantically necessary for the verb, as exemplified in (36).

The little girl cut the paper with the scissors.

The woman watched the show with binoculars.

To summarize there are different kinds of verbs: allow verbs and require verbs. Allow verbs do not necessarily need instrumental phrases, however they accept them. On the other hand, require verbs need them to be semantically complete.

Likewise, in Turkish, a kesme 'cutting' event (require verb) needs an instrumental phrase to be semantically complete. On the other hand, in an izleme 'watching' event (allow verb), the instrumental phrase is not semantically obligatory which means it is not a core participant.

Küçük kız kağıdı makasla kesti.

Little girl paper scissors-INS cut-PAST

'The little girl cut the paper with scissors.'

(38) Kadın gösteriyi dürbünle izledi.

Woman show binocular-INS watch-PAST

'The woman watched the show with binoculars.' 
In her dissertation, Barbu (2020), conducted a cross-linguistic study in four languages (English, Romanian, Spanish and Turkish). The goal of her study was to investigate the status of instruments as arguments or adjuncts. She conducted two experiments per language: the first one was on speakers' semantic intuition and the second one was on their syntactic intuition.

For the semantic study, the subjects were instructed to imagine an event that takes part in a big and empty box, and they were asked to specify what must be in the box for the event to take place. Then the subjects were asked to write, as an open-ended question, the necessary participants for the event to occur. For example, the subjects were asked to write the words they would need for a serving event to happen. In her dissertation, Barbu (2020, p. 69) provides the possible answers that she supplied to her participants:

1. someone to serve and something to be served (a waiter, and a cold soup)

2. someone to serve, something to serve, and someone to be served (a waiter, a cold soup, and a woman)

3. someone to serve and someone to be served (a waiter and a woman)

In the second experiment, speakers were presented with incomplete sentences and asked to complete them with at least one word.

In both English and Turkish, require-instrument verbs prompted more participants than allow-instrument verbs in the semantic task. However, such a difference was not present in the syntactic task (Barbu, 2020).

\subsubsection{Optionality Test}

The optionality test is one of the two most mentioned test in textbooks along with the core participant test (Christie, 2013). This test states that the arguments of a verb are the ones that are syntactically obligatory and adjuncts are optional (Lyons 1968, Chametzky 2000, Bierwisch 2003).

For example, in (39) the element last Tuesday is optional and the elements Kelly and Sam are obligatory. This means, according to the optionality test, when last Tuesday is dropped, as seen in (40) the sentence is grammatical, however when the syntactically obligatory element Sam is dropped in (41) the sentence becomes ungrammatical.

(39) Kelly prodded Sam last Tuesday.

(40) Kelly prodded Sam.

(41) * Kelly prodded last Tuesday. 
However, this test is problematic in some cases, because in English there are some uncontroversial cases where the arguments are optional as seen in (42). The verb to eat has two core participants, and they are both expressed in (42a). In (42b), however, only one is expressed and the sentence remains grammatical.
(42) a. Susie ate a pizza.
b. Susie ate.

According to some linguists, not all adjuncts are optional, there are some obligatory adjuncts as well as mentioned in section 1.1. The fact that there are obligatory adjuncts is another problematic aspect for the optionality test (Jackendoff 1990, Grimshaw and Vikner 1993, Goldberg and Ackerman 2001). In (43a), in Italy is an adjunct; however as shown in (43b) the sentence is ungrammatical when it is dropped.
(43) a. The best tomatoes are grown in Italy.
b. * The best tomatoes are grown.

In pro-drop languages such as Turkish, not only adjuncts can be omitted. In other words, it is possible to drop core participants in context.

In the event yemek (eating) the speakers do not necessarily express both core participants: the eater and what is eaten (see (33) above). Instead, it is possible to drop the both the person who eats (Suzan) and the thing that's eaten (pizza) as seen in (44).
(44) a. Pizza yedi.
Pizza eat-PAST
‘* Ate the pizza.'
b. Suzan yedi.
Susan eat-PAST
'Susan ate.'

In the sentence (45a), sabah sabah (early morning) is optional and considered to be an adjunct. On the other hand, the elements Ceren and Serkan are semantically obligatory. As seen in (45), in Turkish, it is possible to drop semantically obligatory elements as well. 
(45) a. Ceren Serkan’1 sabah sabah kışkırttı.

Ceren Serkan-ACC morning morning prod-PAST

'Ceren prodded Serkan early morning.'

b. Ceren Serkan'1 kışkırttı.

Ceren Serkan-ACC prod-PAST

'Ceren prodded Serkan.'

c. Ceren sabah sabah kışkırttı.

Ceren morning morning prod-PAST

'Ceren prodded early morning.'

d. Ceren kışkırttı.

Ceren prod-PAST

'Ceren prodded.'

Even if in most sentences one could omit internal and external arguments of a Turkish sentence when the context is clear, there are certain constructions that make it harder to omit certain parts of the sentence. For example, according to Knecht (1986), there are some specific rules about omitting the direct object in causative sentences. The direct object of intransitive causative sentences cannot be dropped (46), while the direct object of transitive causative sentence can be dropped (47). In other words, the direct object of the intransitive causative sentence is syntactically obligatory in Turkish.

(46) a. Kadin Gül-ü sandalyeye oturt-tu. Woman Gül-ACC chair-DAT sit-CAUS-PAST

'The woman made Gul sit on the chair.'

b. * Kadin sandalyeye oturt-tu. Woman chair-DAT sit-CAUS-PAST

'The woman made sit on the chair.'

(47) a. Adam polise Gül-ü tutuklat-tı. Man polis-DAT Gül-ACC arrest-CAUS-PAST

'The man made the policeman attested Gul.'

b. Adam Gül-ü tutuklat-tı.

Man Gül-ACC arrest-CAUS-PAST

'The man made attest Gul.'

In short, this test can be used in both languages as there are syntactically optional and obligatory elements in both. However, it is harder to evaluate it in Turkish due to its pro-drop property. To apply the tests, it is essential to know and consider the properties of individual languages. 


\section{Optionality test applied to instruments}

According to this test, instrumental phrases are arguments if the sentence becomes ungrammatical when the instrumental phrase is omitted. On the other hand, they are adjuncts if the sentences are not ungrammatical after dropping them.

In English, it is possible to omit the instrumental phrase in (48a), as seen in (48b). The verb to open is an allow verb.
(48) a. I opened the door with a key.
b. I opened the door.

However, it is important to consider whether it is possible to omit the instrumental phrase with a require verbs as well. The verb to write is an example of a require verb. It is possible to see in (49) that dropping the instrumental phrase with a pen is possible.
(49) a. I wrote on a paper with a pen.
b. I wrote on a paper.

Similarly, in Turkish, for both verb classes, omitting the instrumental phrase is possible. Let's consider the verb to open and to write in Turkish. It is possible to omit the instrumental phrase in the sentence of allow verbs (50a). As seen in (50b) the sentence is still grammatical.

(50) a. Kız kapıyı anahtar-la aç-tı.

Girl door key-INS open-PAST

'The girl opened the door with a key.'

b. Kız kapıyı aç-tı.

Girl door open-PAST

'The girl opened the door.'

(51) a. Çocuk kağıd-a kalem-le yaz-dı.

Boy paper-DAT pen-INS write-PAST

'The boy wrote with a pen.'

b. Çocuk kağıd-a yaz-dı.

Boy paper-DAT write-PAST

'The boy wrote.'

It is also possible to omit the instrumental phrase of sentences with required verbs (50b) and keep its grammaticality (51a). However, it is important to remember that in Turkish it is possible to drop both arguments and adjuncts in the proper context.

To summarize, according to the optionality Test, instruments are classified as adjuncts in both languages. 


\subsubsection{Verb specificity test}

According to the verb specificity test, arguments are restricted to a specific verb or verb class, while adjuncts are not. Different verbs can trigger different arguments, and the same phrase might be an argument for one verb and an adjunct for another verb (Needham and Toivonen, 2011).

(52) The conflict lasted for a month.

(53) I lived in Paris for a month.

In (52), the time phrase for a month is linked to the meaning of the verb to last, so this prepositional phrase is an argument. On the other hand, in (53) the time phrase is not linked to the meaning of the verb to live, thus it is an adjunct.

This test works in Turkish as well. As in English, verbs need different information just like in English. As verbs ask for different information, the same phrase can be an argument for one verb and can be an adjunct for another. For example, in (54 and 55) the verbs sürmek 'to last' and yaşamak 'to live' asks for different participants. The prepositional phrase (PP) bir ay (for a month), is an argument for the verb sürmek (to last) (54), as the verb is asking for a time period. However, the same PP is an adjunct for yaşamak (to live) (55), as that verb does not ask for that information.

(54) Çatışmalar bir ay sür-dü.

Conflict one month last-PAST

'The conflict lasted for a month.'

(55) Paris'te bir ay yaşa-di-m.

Paris one month live-PAST-1PS

'S(he) lived in Paris for a month.'

This test is relevant and works in both languages, but it is not very useful in practice. This test might be useful when it is used in conjunction with the core participant test as both of these tests rely on the core participants that a verb asks and they might complement each other. 


\section{Verb specificity test applied to instruments}

According to Reinhart (2002) instruments can only be added to agentive verbs. That means, according to this test, instruments should classify as arguments because they are only allowed with a specific class of verbs.

There is a similar categorization for the verbs that can take instruments in Turkish as well. As the cross-linguistic study Barbu's (2020) cross-linguistic study shows, the same verbs allow instruments in English and Turkish. Participants used instrumental phrases for allow and require verbs in the semantic task. Those verbs are agentive, for example, in both languages they have mentioned instruments for cut, write, draw (require verbs) and repair, drink and eat (allow verbs). In other words, Barbu agrees with Reinhart's categorization.

To summarize, according to this test, in both languages instruments are categorized as arguments.

\subsubsection{Iterativity test}

According to the iterativity test, in a clause, argument roles cannot iterate because thematic roles required by a verb are assumed to be filled by a syntactic phrase only once (56).

(56) * Chris rented the gazebo to yuppies to libertarians.

However, adjunct roles can be filled more than one time. In other words in a phrase adjuncts can iterate (57) (Needham and Toivonen 2005, Bresnan 1982, Kaplan and Brensnan 1995).

(57) Fred deftly [Manner] handed a toy to the baby by reaching behind his back [Manner] over lunch [Temp] at noon [Temp] in a restaurant [Loc] last Sunday [Temp].

(Bresnan 1982c)

There is a similar distinction in Turkish, as seen in (58) and (59).

(58) * Can adamı kurabiyeyi gör-dü.

John man cookie see-PAST

'John saw the man the cookie.'

(59) Ferdi oyuncağı bebeğe arkasına ulaşarak geçen pazar öğle yemeğinde restoranda ustaca Ferdi toy baby behind-his-back by-reaching last Sunday noon lunch restaurant deftly ver-di. hand-PAST

'Fred deftly handed a toy to the baby by reaching behind his back over lunch at noon in a restaurant last Sunday.'

Similar to English, in Turkish arguments cannot iterate in a clause (58) while adjuncts can (59).

Arguments can have several different semantic roles in a sentence such as manner, time, location, agent, as experiencer, etc. (Carnie 2006). 


\section{Iterativity test applied to instruments}

This test leads to mixed results in terms of categorizing instruments. In (60a), the instrument can be categorized as an argument as it cannot iterate. Contrary, in (60b), the instrument can be categorized as an adjunct as it can be iterated.

(60) a. *I wrote on a paper with a crayon with a pen.

b. The robot opened the door with a key with its robotic hand.

(Goldberg, 2002)

This test leads to mixed results in Turkish like it does in English. In (61a) the instrument patterns as an argument. On the other hand, in (61b), the instrument can be classified as an adjunct, because the instruments can be iterated.

a. * Çocuk kağıda tebeşirle kalemle yaz-dı.

Kid paper-DAT chalk-with pen-INS write-PAST

'She wrote on a paper with a chalk with a pen.'

b. Robot kapiyı anahtarla metal eliyle açtı.

Robot door-ACC key-INS metallic hand-INS open-PAST

'The robot opened the door with a key with its metallic hand.'

In short, it is possible to iterate instrumental phrases in some cases but not in all cases. In other words, this test is inconclusive and leads to mixed results in both languages.

\subsubsection{VP anophora test}

According to Williams (2015, pg. 71), this test suggests that adjuncts can follow do so while arguments cannot (Lakoff and Ross 1976, Needham and Toivonen 2011, Sedivy and Spivey-Knowlton 1994). This is because there is a tight link between the verb and its argument. However, a similar link does not exist between the verb and its adjuncts (Van Luven 2014; Barbu 2020). For example, there is a difference between (62b) and (63b), because tonight and tomorrow are adjuncts in (62). However, sausage and bacon are arguments in (63).

(62) a. Mo might cook sausage tonight...

b. $\quad$....and Lee might do so tomorrow.

(63) a. Mo might cook sausage...

b. *...and Lee might do so bacon. 
There is a similar distinction in Turkish as well. For example, there is a similar difference between (64b) and (65b). Bu akşam (tonight) and yarın akşam (tomorrow night) are adjuncts in (2.1.5), so, they can be used with the helper verb yapmak (to do). In this case, yapmak (to do) does not have its own meaning but has the meaning of the verbs of the sentence precedent.

(64) a. Mete bu akşam sosis pişirebilir... Mete this night sausage cook-might

'Mete might cook sausage tonight...'

b. ...Tekin bunu yarın akşam yapabilir.

Tekin that tomorrow night do-might

'...Tekin might do so tomorrow night'

On the other hand, sosis (sausage) and pastırma (bacon) are arguments in (65). So, they cannot be used with the helper verb yapmak (to do).

(65) a. Mete sosis pişirebilir...

Mete sausage cook-might

'Mete might cook sausage...'

b. *...Tekin bunu pastırma yapabilir.

Tekin that bacon do-might

'...Tekin might do so bacon'

This test works similarly in both languages. However, in English, adjuncts can come after do so, and arguments cannot. Likewise, in Turkish adjuncts can be used with the helper verb yapmak (to do), however arguments cannot be used with it.

\section{VP anaphora test applied to instruments}

According to this test, English instrument PPs pattern with adjuncts, because in both cases, instrumental phrases can come after do so. For example, the verb to eat in (66) is an allow verb (Rissman 2011), and the instrumental phrase can come after do so. Similarly, the verb to write in (67) is a require verb (Rissman 2011), and the instrumental phrase can come after do so in this case as well. In short, according to this test, in English, both allow and require instruments can be categorized as adjuncts.

(66) a. Mo might eat sausage with a fork...

b. $\quad$...and Lee might do so with his hand.

(67) a. Mo might write the question with a pen...

b. $\quad$...and Lee might do so with a chalk. 
Similarly, in Turkish, according to this test, both classes of instrumental phrases are categorized as adjunct, because as seen in (68) and in (69), they can both come before the helper verb yapmak (to do).

(68) a. Mete sosisi çatalla yedi...

Mete sausage-ACC fork-INS eat-PAST

'Mete ate the sausage with a fork...'

b. ...Tekin bunu eliyle yaptı.

Tekin that hand-INS do-PAST

'...Tekin did so with his hand.'

(69) a. Mete soruyu kalemle yazd1...

Mete question-ACC pen-INS write-PAST

'Mete wrote the question with a pen...'

b. ...Tekin bunu tebeşirle yaptı.

Tekin that chalk-INS do-PAST

'...Tekin did so with a chalk'

To summarize, this test categorizes instrumental phrases as adjuncts in both English and Turkish.

\subsubsection{Pseudo-cleft test}

According to the pseudo-cleft test (Hedberg and DeArmond 2009) adjuncts (70a) can occur after do in a VP-focused psuedo-cleft while arguments (70b) cannot.

(70) a. What Sue did in the morning was read a book.

b. * What Marc did to school was go.

In (70a), in the morning is an adjunct as it can follow do. On the other hand in (70b), to school is an argument as it cannot occur after $d o$.

In English and Turkish, the pseudo-cleft constructions and the diagnostic tests are different because those two languages are syntactically different.

English has two kinds of cleft-constructions, wh-clefts and it-clefts (Prince 1978). On the other hand, according to Kornfilt (2013), Turkish also has a pseudo-cleft construction which is used for emphasis. ${ }^{1}$

To use the pseudo-cleft construction as an argumenthood test in Turkish, it is important to understand what can go between the subject and the verb yapmak (the 'do-verb'). In the examples (71) the verb yapmak is in object participle form $(\mathrm{ObjP})$ in 3rd person singular.

\footnotetext{
${ }^{1}$ Turkish, as a pro-drop language, does not have expletive subjects and thus does not allow cleft constructions that begin with it. In other words, Turkish only allows pseudo-clefts that are formed by a headless relative clause or a copula (Turan 1997).
} 
The examples in (71) show that adjuncts can occur between subjects and do-verbs, but arguments cannot, in Turkish pseudo-cleft constructions.

(71) a. Suzan'ın sabah yap-tı-ğg1 kitap okumak-t1. Suzan-GEN morning do-ObjP-3SG book read-PAST

'What Susan in the morning did was read a book.'

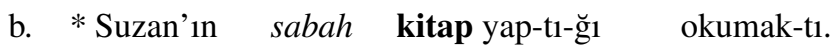
Suzan-GEN morning book do-ObjP-3SG read-PAST

'What Susan in the morning did was read a book.'

c. * Suzan'ın kitap yap-t1- $\breve{g}_{1} \quad$ sabah okumak-t1. Suzan-GEN book do-ObjP-3PS morning read-PAST

'What Susan in the morning did was read a book.'

In (71a) sabah 'morning' is an adjunct and when it occurs between the subject and the do-verb, the sentence is grammatical in Turkish. However, in (71b) and (71c) kitap 'book' is an argument; having it between the subject and do-verb makes the sentence ungrammatical.

In short, this test can be used to identify arguments and adjuncts in both languages but in different ways due to syntactic differences.

\section{Pseudo-cleft test applied to instruments}

According to Hedberg and DeArmond (2009), this test categorizes instruments as adjuncts in English (72). What I did with the pens was write.

In (72), with the pens is the instrumental phrase and it can occur after the do. So, according to this test, instrumental phrases are adjunct like.

As mentioned above, in Turkish adjuncts but not arguments can occur between the subject and the do-verb. This test categorizes instruments as adjunct-like as they can occur in that position.

$$
\begin{aligned}
& \text { Mehmet'in kalemle yap-tı- } \breve{g}_{1} \quad \text { yazmaktı. } \\
& \text { Mehmet-GEN pen-INS do-ObjP-3SG write-PAST } \\
& \text { 'What Mehmet did with the pens was write.' }
\end{aligned}
$$

In (73), kalemle 'with pens' is the instrumental phrase and when it appears between the subject and the do-verb, the sentence is grammatical in Turkish.

To sum up, according to the Pseudo-cleft test, instrumental phrases are adjunct-like in both languages. 


\subsubsection{Alternation test}

According to this test, arguments can alternate with subjects and objects, but adjuncts cannot (Needham and Toivonen 2011).

(74) a. The garden swarmed with bees.

b. The bees swarmed in the garden.

(Needham and Toivonen 2011, p. 407)

According to this test the phrase with the bees is an argument because it alternates with the subject (74). Likewise, to Lisa is an argument because it alternates with an object in (75).

(75) a. Mandy gave a present to Lisa.

b. Mandy gave Lisa a present.

(Needham and Toivonen 2011, p. 408)

This test also work similarly in Turkish. Arguments can alternate with subjects and objects in Turkish as well. In (76), the phrase arılarla 'with bees' is an argument according to this test because it alternates with the subject.

(76) a. Bahçe arılarla doldu.

Garden bee-PL-INS swarm-PAST

'The garden swarmed with bees.'

b. Arılar bahçeye doldu.

Bee-PL garden-DAT swarm-PAST

'The bees swarmed the garden.'

According to this test, the phrase hediye 'present' in (77) is an argument as that phrase can alternate with the object.

(77) a. Merve hediyeyi Lale'ye verdi.

Merve present-ACC Lale-DAT give-PAST

'Merve gave the present to Lale.'

b. Merve Lale'ye hediye verdi.

Merve Lale-DAT present give-PAST

'Merve gave Lale a present.' 


\section{Alternation test applied to instruments}

According to this test, instrumental phrases are arguments in both languages as they can alternate with the subject in English (78) and in Turkish (79).

(78) a. The door was opened with the key.

b. The key opened the door.

(79) a. Kapı anahtarla açıldı. Door key-INS open-PASS-PAST

'The door opened with the keys.'

b. Anahtar kapıyı açtı.

Key door-ACC open-PAST

'Key door-ACC open-PAST.'

In short, the Alternation Test can be used in both languages and according to this test, instrumental phrases can be categorized as arguments.

\subsection{Test that cannot be used in Turkish}

\subsubsection{Relative ordering test}

The Relative ordering test is based on the observation that the relative ordering of arguments in a sentence is stricter than the ordering of adjuncts. Arguments are typically directly adjacent to the verb in English (Jackendoff, 1977). On the other hand, adjuncts are more free in a sentence. In the sentences in (80), cheerfully is an adjunct, and as seen in (80) it can be placed differently in a sentence, without making the sentence ungrammatical.

(80) a. Cheerfully, Tobias ate the apple.

b. Tobias cheerfully ate the apple.

c. Tobias ate the apple cheerfully.

On the other hand, Tobias and an apple are the arguments of the sentences (81). When changing the relative ordering of the argument of (81a) an apple, it makes the sentence ungrammatical as seen in (81b and 81c).

(81) a. Tobias ate an apple.

b. * Tobias ate cheerfully an apple.

c. * Tobias an apple ate cheerfully. 
Even if Turkish is generally accepted as an SOV language, according to Hoffman (1995), it has fairly free word order. In other words, in Turkish, it is possible to play with the ordering of the arguments. It is grammatical to say all the sentences exemplified in (81), and there are even more possibilities. For example, in the sentences in (82), Ahmet is the internal argument of the sentence. However, it is still possible to reorder it.
(82) a. Fatma Ahmet'i gör-dü.
Fatma Ahmet-ACC see-PAST
'Fatma saw Ahmet.'
b. Ahmet'i Fatma gör-dü.
Ahmet-ACC Fatma see-PAST
'Fatma saw Ahmet'
c. Fatma gör-dü Ahmet'i.
Fatma see-PAST Ahmet-ACC
'Fatma saw Ahmet'
d. Ahmet'i gördü Fatma.
Fatma Ahmet-ACC see-PAST Fatma
'Fatma saw Athmet.'

Adjuncts are flexible in Turkish as well. In the sentences in (83) dün is an adjunct and all variations are grammatical (Hoffman, 1995).
(83) a. Dün Fatma Ahmet'i gör-dü.
'Yesterday, Fatma saw Ahmet.' Yesterday Fatma Ahmet-ACC see-PAST
b. Fatma dün Ahmet'i gör-dü . Fatma yesterday Ahmet-ACC see-PAST
'Fatma saw Ahmet, yesterday.'
c. Fatma Ahmet'i dün gör-dü . Fatma Ahmet-ACC yesterday see-PAST
'Fatma saw Ahmet yesterday.'
d. Fatma Ahmet'i gör-dü dün.
Fatma Ahmet-ACC see-PAST yesterday
'Fatma saw Ahmet yesterday.'

(Hoffman 1995, pp.14)

For the sentences (82c) and (83d) I do not agree with Hoffman (1995). According to my intuition, in Turkish, for a sentence to be grammatical, the verb needs to come at the end of the sentence. Otherwise the sentence is ungrammatical. According to Hengirmen (1997), Turkish sentences are grammatical if the verb is at the end of the sentence and they are ungrammatical. However, as illustrated by the examples and judgements provided by Hoffman, there is variation in this respect. 
In short, Turkish has more flexible word ordering than English and it is possible to change the ordering of both arguments and adjuncts. Therefore, this test can be used in English to categorize words and phrases as arguments or as adjuncts, however, it is not as useful in Turkish.

\section{Relative ordering test applied to instruments}

According to this test, instrument phrases are adjuncts if it is possible to reorder them, and they are arguments if it is not possible to reorder them.

As mentioned earlier, there are verbs that require an instrument and those that allow an instrument. In (84a and $84 \mathrm{~b})$ the verb cut is a verb that requires instruments. When instrumental phrase is reordered, the sentence becomes ungrammatical, as illustrated in (84b).

\section{(84) a. I cut the paper with scissors. \\ b. * I cut with scissors the paper.}

The instrumental phrase of the sentence that contains an allow verb (for example eat) as in (85a and 85b), cannot be reordered as well. When the instrumental phrase comes after the verb, the sentence becomes ungrammatical (85b).

(85) a. She ate the soup with a spoon.

b. * She ate with a spoon the soup.

In short, according to the relative ordering test, one cannot reorder the instrumental phrases in English and therefore this property this test identifies instruments as arguments.

Even though the relative ordering test is not helpful in picking out arguments and adjuncts in Turkish, I will nevertheless show here how instruments pattern according to this test. In Turkish, instrumental phrases can be put in different places in a sentence as seen in (86).
a. K1z kağıdı makasla kesti.
Girl paper-ACC scissor-INS cut-PAST
'The girl cut the paper with scissors.'
b. K1z makasla kağıdı kesti.
Girl scissor-INS paper-ACC cut-PAST
'The girl cut the paper with scissors.'

The relative ordering test indicates that instruments are argument in English. The relevant data are contradicting in Turkish, but recall that this test is not very useful in Turkish, since Turkish word order is generally quite free. 


\subsubsection{WH-word conjunction test}

Some wh-words refer to arguments and some refer to adjuncts. For example; when and where in (87) refer to adjuncts. On the other hand, who refers to a subject (external argument) in (88a) and what refers to an internal argument in (88b) (Melchin and Toivonen 2018).

(87) a. When did Mary find the ring?

b. Where did Sue bring the keys?

(88) a. Who ate?

b. What did he find?

In the wh-word conjunction test, in English, two wh-words that refer to arguments with different semantic roles cannot be conjoined. However, two wh-words that refer to adjuncts with different semantic roles can be conjoined. Similarly, if a wh-word that refers to an argument and one that refers to an adjunct are conjoined, the sentence becomes ungrammatical (DeArmond and Hedberg 1998, Needham and Toivonen 2011, Melchin and Toivonen 2018 and Gračanin-Yuksek 2007).

In (89a), the picture and Kim are two arguments of the verb to show, and they have different semantic roles, so different wh-words refer to them (Browne 1972, Gračanin-Yuksek 2007). As seen in (89b), what refers to the picture and who $(\mathrm{m})$ refers to Kim. However, the conjunction of those wh-words makes the sentence ungrammatical.

(89) a. Sam showed Kim a picture.

b. * What and who(m) did Sam show?

On the other hand, in sentence (90a), in Minneapolis and on Friday are adjuncts. As seen in (90b), where refers to in Minneapolis and when refers to on Friday. As both of them are adjuncts, the wh-words that refer to them can be conjoined and the sentence is grammatical in English.

(90) a. Jolanda met a friend in Minneapolis on Friday.

b. Where and when did Jolanda meet a friend?

In sentence (90a), a picture is an argument and last night is an adjunct. In (90b), what refers to a picture and when refers to last night; the conjunction of those two wh-verbs makes the sentence ungrammatical.

(91) a. Sam showed a picture last night.

b. * What and when did Sam show? 
An argument wh-word can sometimes be co-ordinated with an adjunct wh-word (Gračanin-Yuksek 2007). For example (92) is an acceptable sentence.

(92) What and why did you eat?

(Gračanin-Yuksek 2007, 40)

However, it is only acceptable in some specific cases. It is acceptable with the reading in (93a) but not with the reading in $(93 b)$.

(93) a. What did you eat and why did you eat at all?

b. What did you eat and why did you eat it?

The wh-word conjunction test works the same way in Turkish, but since in Turkish, all arguments are optional, there are no obligatory arguments that could give the effect that it does in English.

In (94a), resim (a picture) and Serdar are two arguments of the verb to show, and they have different semantic roles, so different wh-words refer to them (Browne 1972, Gračanon Yuksek 2007). As seen in (94b), neyi (what) refers to resim (a picture) and kime (who(m)) refers to Serdar.

(94) a. Özge Serdar'a resim gösterdi.

Ozge Serdar-DAT picture show-PAST

'Ozge showed a picture to Serdar.'

b. Özge kime neyi gösterdi?

Ozge who-DAT what-ACC show-PAST

'Who(m) and what did Ozge show'

A possible explanation why the two- wh-words can conjoin without making the sentence ungrammatical is that Turkish is a wh-in-stu language and no wh-movement is required for any wh-sentences (Issever, 2009).

Similarly, conjoining two wh-words that refer to two adjuncts that have two different semantic roles does not make the question sentence ungrammatical. For example, in (95a), Istanbul'da (in Istanbul) and Cuma günü (on Friday) are two adjuncts of the verb buluşmak (to meet), and they have different semantic roles, so different wh-words refer to them. As seen in (95b), nerede (where) refers to Ístanbul'da (in Istanbul) and ne zaman (when) refers to Cuma günü (on Friday). In Turkish, like in English, those two wh-words can conjoin without making the sentence ungrammatical.

(95) a. Beren arkadaşıyla İstanbul'da Cuma günü buluştu.

Beren friend-POSS-INS Istanbul-LOC Friday day meet-PAST

'Beren met her friend in Istanbul on Friday.'

b. Beren arkadaşıyla nerede ve ne-zaman buluştu?

Beren friend-POSS-INS where and when meet-PAST

'When and where did Beren meet with her friend?' 
This test can be used in English to categorize words and phrases as arguments and adjuncts. However, it cannot be used in Turkish, because this test does not show any difference between arguments and adjuncts in Turkish.

\section{WH-word conjunction test applied to instruments}

To apply this test with instrumental phrases, I combine them both with clear arguments and with clear adjuncts. For example, in (96a), I combine the instrumental phrase with the key with the argument the door. In the sentence (96b), the wh-word how refers to with the key and what refers to the door. In this case, conjoining the wh-words makes (96b) ungrammatical.
(96) a. Sam opened the door with the key last night.
b. * How and what did Sam open last night?

In (97a), I combine the instrumental phrase with the key and a clear adjunct last night. As seen in (97), how refers to the instrumental phrase with the key and when refers to the clear adjunct last night. Conjoining those wh-words does not make (97) ungrammatical, which indicates that according to this test, instrumental phrases are adjunct-like.

\section{(97) a. Sam opened the door with the key last night. \\ b. How and when did Sam open the door?}

As mentioned in the previous section, this test is not a good indicator of Turkish arguments and adjuncts, because wh-words that refer to arguments with different semantic roles can be conjoined, as shown in (98b). The wh-words corresponding to the instrumental phrase can be conjoined with the wh-words that corresponds to arguments and to adjuncts as in (98c).

(98) a. Levent dün akşam kapıyı anahtarla açtı. Levent yesterday night door-ACC key-INS open-PAST

'Levent opened the door with a key last night.'

b. Levent dün akşam neyi nasıl açtı?

Levent yesterday night what and how open-PAST

'With what and how did Levent opened last night?'

c. Levent kapıyı anahtarla ne-zaman ve nasıl açtı?

Levent door-ACC key-INS when and how open-PAST

'When and how did Levent open the door with the key?' 


\subsection{Summary}

To conclude, according to the argumenthood tests, it is not possible to conclusively determine whether instruments are arguments or adjuncts. These tests reveal mixed findings in both languages. Table 1 shows how those tests categorize instruments in English and in Turkish. The argumenthood tests seem to work similarly in both languages.

\begin{tabular}{|c|c|c|}
\hline Test & English & Turkish \\
\hline Core Participant Test & ARG or ADJ & ARG or ADJ \\
\hline Optionality Test & ADJ & ADJ \\
\hline Verb Specificity Test & ARG & ARG \\
\hline Iterativity Test & ARG or ADJ & ARG or ADJ \\
\hline VP Anaphora Test & ADJ & ADJ \\
\hline Pseudocleft Test & ADJ & ADJ \\
\hline Alternation Test & ARG & ARG \\
\hline Relative ordering Test & ARG & N/A \\
\hline WH-Word Conjunction Test & ADJ & N/A \\
\hline
\end{tabular}

Table 1: Categorization of Instruments in English and Turkish.

\section{Study}

\subsection{Methods}

This is a reaction time study conducted in two languages, Turkish and English. The goal was to test differences in reaction time between indirect objects, adjuncts, and instruments. I used three kinds of verbs: regular ditransitive verbs (e.g., give, ask, deliver), verbs that allow instruments ("allow verbs"; e.g., open, wash, eat), and verbs that require instruments ("require verbs"; e.g. cut, write, paint) (Rissman 2015, Barbu 2020).

In (99), the verb give is an example of a ditransitive verb. Some other verbs that fall under the same group are: sell, ask, bring, show, and deliver.

(99) Susie gave her bike to John.

In (100), the verb open is an allow verb. Some other verbs from the same group are: wash, eat, drink, clean, and defend.

(100) Amelia opened the door with the key.

In (101), the verb cut is a require verb. Some other examples for that group are: draw, paint, write, slice, and comb.

(101) Thomas cut the papers with scissors. 
The study used these three types of verbs because in all these verbs, it is possible to have at least one direct object. The ditransitive sentences will have a subject (external argument), a direct object, a beneficiary or a recipient (indirect object) and a ditransitive verb. The allow and require sentences used in this study include a subject, a direct object, and an instrumental phrase. There were two types of adjuncts in the study. There were clear adjuncts and with-adjuncts. The with-adjuncts are the subcategory of clear adjuncts that have the preposition with in English and instrumental case $-(y) l e$ in Turkish.

All sentences were designed to have at least one direct object, because in a pilot study conducted previously, the stimuli were short and the processing time for the sentences was too fast for an online self-paced study to detect differences between different classes. This study therefore had longer sentences to slow down processing times. However, I did not want to add too many unnecessary adjuncts, which could complicate my analysis as this study is comparing adjuncts to clear arguments and instruments.

In this study there were two sets of sentences to touch on two different points:

1) The first set included sentences with verbs that can take instruments. Both allow and require verbs were included. The intention was to investigate the response time difference between instruments and adjuncts.

In (102), examples for allow sentences are demonstrated. The with her clean hand phrase in (102a) is an instrumental phrase. On the other hand, with exceptional joy in (102b) is a manner adjunct.

(102) a. Amelia opened the door with her clean hand.

b. Amelia opened the door with exceptional joy.

Similarly, in (103) the require sentences are demonstrated. The with plastic scissors phrase in (103a) is the instrumental phrase and the with tremendous sadness phrase in (103b) is a manner adjunct.

(103) a. Thomas cut the papers with plastic scissors.

b. Thomas cut the papers with tremendous sadness.

In the study there were natural and anomalous versions for each category. That is, there were anomalous counterparts for each category explained above. In (104) the anomalous versions of the allow sentences are demonstrated.

(104) a. Amelia opened the door with her curly hand.

b. Amelia opened the door with square joy. 
Similarly, in (105) the anomalous version of require sentences are exemplified.

(105) a. Thomas cut the papers with sandy scissors.

b. Thomas cut the papers with slippery sadness.

2) The ditransitive sentences were important to see the reaction time difference between arguments and adjuncts.

In both the Turkish and English studies, there were ditransitive sentences with either an indirect object (all ditransitive sentences will have a direct object) or an adjunct. There were two versions of ditransitive sentences as well, natural and anomalous.

In (106), the sentences with two internal arguments (106a) and a direct object and an adjunct (106b) are demonstrated.

(106) a. Samantha sold her car to James.

b. Samantha sold her car quickly.

Similarly, in (107) the anomalous versions of transitive sentences are exemplified.

(107) a. George gave his bike to the tree.

b. George gave his bike tightly.

\begin{tabular}{|c|c|}
\hline Verb & Distinctions \\
\hline Allow/Require & with-instrument OR with-adjunct \\
\hline Ditransitive & Argument OR Adjunct \\
\hline
\end{tabular}

Table 2: Types of stimuli included for both natural and anomalous sentences.

In allow, require sentences and ditransitive sentences, there were two versions, natural and anomalous . According to an eye-tracking study, there is a greater effect between anomalous arguments, adjuncts and instruments than between natural sentences (Boland 2005). By having these two sets of sentences I wanted to see if a similar effect could be found in a reaction time study as well.

The instrument sentences included an instrument and an adjective that modifies the instrument, in both English and Turkish. For natural sentences, the adjectives were plausible for the instrument. On the other hand, for the anomalous sentences, the adjectives were implausible for the instrument. A natural instrument sentence in Turkish is provided in (108a) and an anomalous instrument sentence is exemplified in (108b). In (108a), üşümüşs 'cold' is a plausible adjective for the instrument $e l$ 'hand'; however, in (108b), yeni 'new' is an implausible adjective for the same instrument. 
(108) a. Elif kapıyı üşümüş eliyle açtı.

Elif door-ACC cold hand-POSS-INS open-PAST

'Elif opened the door with her cold hand.'

b. Elif kapıyı yeni eliyle açtı.

Elif door-ACC new hand-POSS-INS open-PAST

'Elif opened the door with her new hand.'

Similarly in English, a natural instrument sentence is demonstrated in (109a) and an anomalous example is in (109b).

(109) a. Sue closed the door with her cold hand.

b. ? Sue closed the door with her modern hand.

In the natural sentences $(110 \mathrm{a}, 111 \mathrm{a})$, the adjective that modifies the with-adjunct is plausible for that adjunct. On the other hand, for the anomalous sentences $(110 \mathrm{~b}, 111 \mathrm{~b})$ the adjective that modifies the instrumental adjunct is implausible.

(110) a. Jale kağıtları büyük özenle kesti.

Jale paper-PL-ACC big care-INS cut-PAST

'Jale cut the papers with a lot of care.'

b. ? Jale kağıtları geniş özenle kesti.

Jale paper-PL-ACC large care-INS cut-PAST

'Jale cut the papers with a large care.'

(111) a. John cut the papers with great care.

b. ? John cut the papers with blue care.

Half of the ditransitive sentences had a benefactives as their second complement. In the natural sentences the recipients were plausible for the verb in both languages as seen in (112a, 113a). On the other hand, for anomalous sentences the recipients were implausible for the verb (112b, 113b).

a. Bülent bisikletini Reyhan'a verdi.

Bulent bike-POSS-ACC Reyhan-DAT give-PAST

'Bulent gave his bike to Reyhan.'

b. ? Bülent bisikletini ağaca verdi.

Bulent bike-POSS-ACC tree-DAT give-PAST

'Bulent gave his bike to a tree.'

(113) a. Sophia gave her bike to Philippe.

b. ? Sophia gave her bike to the trash. 
The other half of ditransitive sentences had an adjunct. In the natural sentences the adjuncts were plausible for the internal argument (114a, 115a). However, in the anomalous sentences the adjuncts were implausible (114b, 115b).

(114) a. Ayça bisikletini mecburen verdi.

Ayca bike-POSS-ACC compulsorily give-PAST

'Bulent gave his bike compulsorily.'

b. ? Ayça bisikletini oldukça verdi.

Ayça bike-POSS-ACC quite give-PAST

'Ayça quite gave his bike.'

(115) a. George gave his bike voluntarily.

b. ? George gave his bike tightly.

In this section I described the verbs that I used and the sentence formations. In sections 3.1.1 and 3.1.2 I will discuss the Turkish and the English studies in more detail and explain the design of the experiment.

\subsubsection{Turkish reaction time study}

The reaction time study was designed to gauge processing time differences between arguments, adjuncts and instruments in Turkish and in English.

\section{Subjects}

Seventy-two self-reported Turkish native speakers (47 F, 24 M) participated in this Reaction Time Study, 7 participants were erased. The eligibility criteria were:

1) being a native Turkish speaker,

2) being at least 18 years of age.

Participants were recruited online through social media, and there was no compensation. Participation in the study was voluntary and the participants had the option to withdraw their participation anytime.

\begin{tabular}{|c|c|}
\hline Age Group & \# of participants \\
\hline $18-22$ & 2 \\
\hline $23-40$ & 29 \\
\hline 41 and above & 34 \\
\hline
\end{tabular}

Table 3: Speakers' age for Turkish reaction time study. 


\section{Design and Instruction}

The reaction time study was the main part of my proposed study. It was done online using PsychoPy.

The participants were asked to read the sentences, and answer a very simple question: Is this sentence natural? If the participants were answering the survey from their computers, they had to press $\mathrm{N}$ for natural sentences, and $\mathrm{A}$ for anomalous sentences. On the other hand, if the participants were answering the survey from their tablets or their phones, they pressed a green dot on the left side of their screen for natural sentence and a red dot on the right side of their screen for anomalous sentences.

The Turkish and English studies each contained 6 allow, 6 require and 6 ditransitive verbs as targets and those verbs were taken from Barbu's (2020) Turkish study. However, Barbu (2020) only tested verbs and not sentences. There were 24 sentences per group, with half of the sentences in each group being anomalous.

Those target sentences were divided into two surveys in order to make it possible to compare different sentences with the same verbs while at the same time making sure that the same participants would not see near-identical sentences. With this study design, there were two sentences per verb per survey, but neither survey included two sentences with the same verb that were directly compared in the analysis. The filler sentences were the same for both surveys.

For the ditransitive sentences, survey A had bolded ones in the table and survey B had italicized ones (Table 4).

\begin{tabular}{|c|c|c|c|c|}
\hline & ARG - Nat & ARG - Anom & ADJ - Nat & ADJ - Anom \\
\hline give & $A$ & B & B & $A$ \\
\hline sell & $A$ & B & B & $A$ \\
\hline ask & $A$ & B & B & $A$ \\
\hline bring & B & $A$ & $A$ & B \\
\hline show & B & $A$ & $A$ & B \\
\hline deliver & B & $A$ & $A$ & B \\
\hline
\end{tabular}

Table 4: Distribution of arguments and adjuncts with ditransitive verbs in surveys A and B

In other words, for the verb vermek 'to give' the participants of Survey A saw the argument natural (116a) and adjunct anomalous (116b) sentences, and the participants of Survey B saw the argument anomalous (116c) and adjunct natural (116d) sentences.

(116) a. Bülent bisikletini Reyhan'a verdi. Bulent bike-POSS Reyhan-DAT give-PAST

'Bulent gave his bike to Reyhan.'

b. Soner bisikletini oldukça verdi. Soner bike-POSS pretty give-PAST

'Soner pretty gave his bike.' 
c. Soner bisikletini ağaca verdi.

Soner bike-POSS tree-DAT give-PAST

'Soner pretty gave to the tree.'

d. Bülent bisikletini mecburen verdi.

Bulent bike-POSS compulsorily give-PAST

'Bulent gave his bike compulsorily.'

Similarly Table 5 shows the distribution of instruments and with-adjuncts for require verbs, and Table 6 demonstrates the instruments and with-adjuncts examples for allow verbs.

\begin{tabular}{|c|c|c|c|c|}
\hline & INS - Nat & INS - Anom & With-ADJ - Nat & With-ADJ - Anom \\
\hline cut & $A$ & B & B & $A$ \\
\hline draw & $A$ & B & B & $A$ \\
\hline paint & $A$ & B & B & $A$ \\
\hline write & B & $A$ & $A$ & B \\
\hline slice & B & $A$ & $A$ & B \\
\hline comb & B & $A$ & $A$ & B \\
\hline
\end{tabular}

Table 5: Distribution of arguments and adjuncts with require verbs in surveys A and B

\begin{tabular}{|c|c|c|c|c|}
\hline & INS - Nat & INS - Anom & With-ADJ - Nat & With-ADJ - Anom \\
\hline open & $A$ & B & B & $A$ \\
\hline wash & $A$ & B & B & $A$ \\
\hline eat & $A$ & B & B & $A$ \\
\hline drink & B & $A$ & $A$ & B \\
\hline clean & B & $A$ & $A$ & B \\
\hline defend & B & $A$ & $A$ & B \\
\hline
\end{tabular}

Table 6: Distribution of arguments and adjuncts with allow verbs in surveys A and B

In each survey, there were 12 allow, 12 require and 12 ditransitive sentences as target sentences. There were also 48 filler sentences. The fillers were the same for both surveys. 48 fillers were deemed to be enough since the ditransitive sentence and the instrumental sentences differed from each other substantially.

The sentences were shown one by one on participants' screens in a random order. The participants were asked whether the sentences were natural in Turkish. 


\section{Data elimination}

Participants participated in this experiment by either using their phones/tablets or their computer. However, the phones/tablets and computer data were not comparable. The reaction times were much longer for the computer data than the phone/tablet data. There were not enough data to run a separate experiment with the computer data, so it has been eliminated. As well, the data collected was cleaned by deleting the sentences with the wrong responses for each participant. For example, if a participant said that a natural sentence is anomalous, that answer is deleted. Also, 7 Turkish participants were erased as they got most of the fillers wrong.

In the Turkish experiment around $1.2 \%$ of individual responses was excluded in addition to all data from the 7 participants. A data point were excluded if the participant indicated a natural sentence as anomalous or vice versa. $58 \%$ of the deleted data contained anomalous sentences and the rest contained natural sentences. In the Turkish experiment most wrong answers (39\%) were with-adjunct phrases of allow verbs. However, there were fewer wrong answers for with-adjunct phrases of require verbs (7\%). Similarly, there were more wrong answers for instrumental phrases of allow sentences (24\%) than require sentences (3\%). Also, arguments (8\%) were excluded less than adjuncts $(19 \%)$.

\subsubsection{English reaction time study}

The reaction time study was designed to gauge processing time differences between arguments, adjuncts and instruments in Turkish and in English.

\section{Subjects}

In the English Reaction Time Study there were ninety-one (53 F, 38 M) participants, 12 participants were erased. The participation requirement was to be at least 18 years of age. The participants were recruited using Carleton University's SONA system and through social media. For compensation SONA participants received $0.25 \%$ course credit towards their first year cognitive science or psychology courses.

\begin{tabular}{|c|c|}
\hline Age Group & \# of participants \\
\hline $18-22$ & 57 \\
\hline $23-40$ & 13 \\
\hline 41 and above & 9 \\
\hline
\end{tabular}

Table 7: Speakers' age by experiment (English). 


\section{Design and Instructions}

The design of the Reaction Time Study in English was the same as the Turkish study, and the sentences were comparable as well. I used the same verbs for both languages and the English sentences mostly corresponded to Turkish sentences. I only made some changes to have more natural sentences in both languages (Appendix A and B). Otherwise, the English reaction time study was identical to the Turkish one.

\section{Data elimination}

Participants participated in this experiment by either using their phones/tablets or their computer. However, the phones/tablets and computer data were not comparable. Like in the Turkish study, the reaction times of computers were longer than phone/tablet. There were not enough data to run a separate experiment with the computer data, so it has been eliminated. As well, the data collected was cleaned by deleting the sentences with the wrong responses for each participant. For example, if a participant said that a natural sentence is anomalous, that answer is deleted. Also, 12 English participants were erased as they got most of the fillers wrong.

In the English experiment around 1.8\% of individual responses were excluded in addition to all the data from the 12 participants. A data point was excluded if a participant indicated a natural sentence as anomalous or vice versa. $78 \%$ of the deleted data contained anomalous sentences and the rest contained natural sentences. In the English experiment, contrary to the Turkish experiment, most wrong answers were with-adjunct phrases of require verbs (31\%), however, there were fewer wrong answers for with-adjunct phrases of allow verbs (12\%). There were also more wrong answers for instrumental phrases of require sentences (20\%) than allow sentences (9\%). The sentences containing arguments $(15 \%)$ were excluded more than sentences containing adjuncts (13\%).

\subsubsection{Stimulus Norming Study}

The stimuli used in the experiment were based on Barbu's (2020) verbs and my judgements. A stimulus norming study was conducted before running the reaction time experiment in both languages to make sure my judgements were valid. There were seven participants (4 F, 2 M, 1 unspecified) in the Turkish norming study and six participants (4 F, $2 \mathrm{M}$ ) in the English one. The participants who participated in the norming study were not allowed to participate in the reaction time study.

The questionnaire was designed using Qualtrics and the link was distributed by email and using WhatsApp to the participants. In the stimulus norming study participants were shown natural and anomalous sentences and they were asked to rate the naturalness of these sentences on a scale of 1 to 5 with 1 being 'this does not sound like a natural sentence' and 5 being 'this sounds like a completely natural sentence.' The purpose of the norming study was to check that other speakers agreed with my own judgments about which sentences sounded natural and which sentences sounded odd. 


\subsection{Results}

\subsubsection{English}

The means and standard deviations of reaction times of natural and anomalous English sentences are demonstrated in Table 8.

\begin{tabular}{|ccccc|}
\hline Normality & Phrase & Verb & Mean & Standard Deviation \\
\hline Natural & ADJ & Ditransitive & 690 & 36 \\
& & Allow & 692 & 38 \\
& & Require & 690 & 39 \\
\hline & ARG/INS & Ditransitive & 690 & 38 \\
& & Allow & 691 & 36 \\
& & Require & 695 & 35 \\
\hline \hline Anomalous & ADJ & Ditransitive & 690 & 36 \\
& & Allow & 691 & 33 \\
& & Require & 700 & 36 \\
\hline & ARG/INS & Ditransitive & 690 & 36 \\
& & Allow & 690 & 40 \\
& & Require & 690 & 38 \\
\hline
\end{tabular}

Table 8: Mean reaction times (in ms) for English sentences

The data is normally distributed and it follows the homogeneity of variance assumption of ANOVA. In a $3 \mathrm{x}$ $2 \times 2$ design, the verb classes (allow, required, ditransitive), phrases (adjunct phrase, argument/instrument phrase) and normality (natural, anomalous) were compared. In other words, there are three independent variables that could influence the response times, 1) the verb types that the sentence contains, 2) whether the sentence contains an adjunct or either a clear benefactive argument (for ditransitive verbs) or instrument (for instrument verbs) and 3) normality (natural vs. anomalous).

A three way ANOVA shows that there is no significant main effect of these groups $\left(F_{\text {verb }}(2,1468)=0.274, p\right.$ $=0.760, F_{\text {phrase }}(1,1468)=0.086, p=0.769$, and $\left.F_{\text {normality }}(1,1468)=1.52, p=0.218\right)$. There is however a significant interaction between phrase and normality $(F(1,1468)=6.3, p=0.012)$, as demonstrated in Figure 1.

As seen in Figure 1, the sentences with adjunct phrases are read faster in English when the sentence is natural and read slower when it is anomalous. However, it is the opposite for the sentences containing argument or instrument phrases, that is the participants read them faster when the sentences are anomalous and slower when they are natural. According to a Tukey post hoc test, there is a significant difference between natural and anomalous sentences with ADJ phrases $(p=0.045)$. 


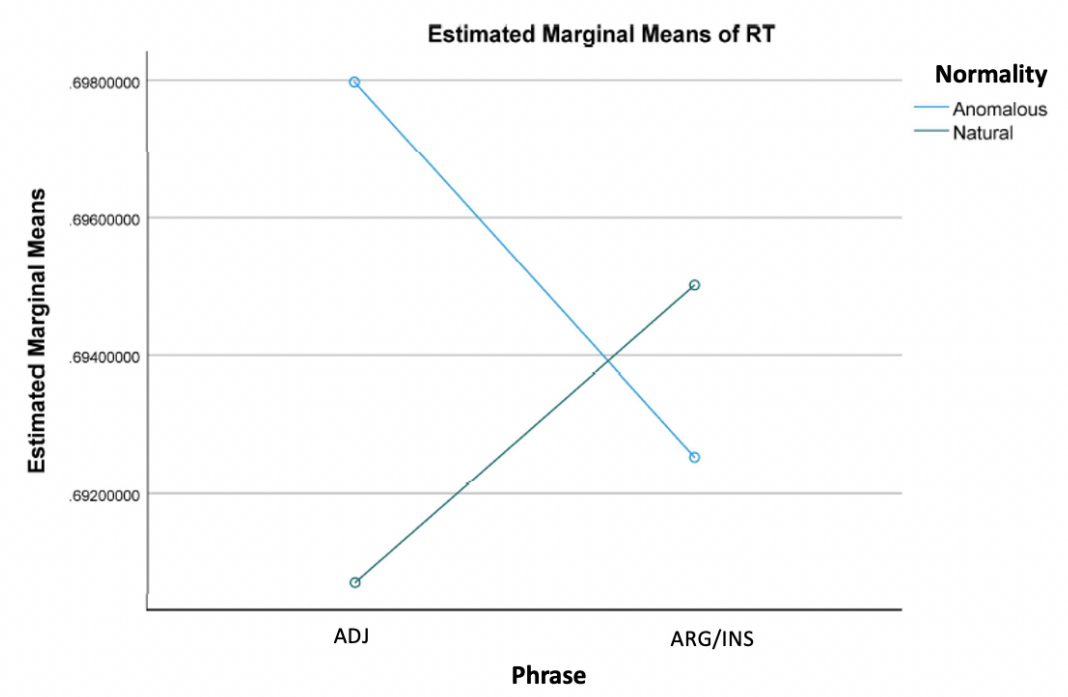

Figure 1: Effect of normality on RTs of ADJ and ARG/INS phrases in English

\subsubsection{Turkish}

The means and standard deviations of reaction times of the Turkish sentences are demonstrated in the Table 9 below.

\begin{tabular}{|ccccc|}
\hline Normality & Phrase & Verb & Mean & Standard Deviation \\
\hline Natural & ADJ & Ditransitive & 700 & 33 \\
& & Allow & 700 & 31 \\
& & Require & 699 & 34 \\
\hline & ARG/INS & Ditransitive & 699 & 33 \\
& & Allow & 699 & 32 \\
& & Require & 699 & 34 \\
\hline \hline Anomalous & ADJ & Ditransitive & 704 & 30 \\
& & Allow & 707 & 30 \\
& & Require & 700 & 33 \\
\hline & ARG/INS & Ditransitive & 704 & 31 \\
& & Allow & 700 & 33 \\
& & Require & 702 & 32 \\
\hline
\end{tabular}

Table 9: Mean reaction times (in ms) for Turkish sentences

The data is normally distributed and it follows the homogeneity of variance assumption of ANOVA. In a $3 \mathrm{x}$ $2 \times 2$ design, the verb classes (allow, required, ditransitive), phrases (adjunct phrase, argument/instrument phrase) and normality (natural, anomalous) were compared. In other words, there are three independent variables that could influence the response times, 1) the verb types that the sentence contains, 2) whether the sentence contains an adjunct or either a clear benefactive argument (for ditransitive verbs) or instrument (for instrument verbs) and 3) normality 
(natural vs. anomalous).

A three-way ANOVA shows that there is no significant main effect of verb group $\left(F_{v e r b}(2,1946)=0.117, p\right.$ $=0.89)$ or phrase $\left(F_{\text {phrase }}(1,1946)=0.247, p=0.619\right)$. This test showed a significant main effect for normality $\left(F_{\text {normality }}(1,1946)=23, p<0.0001\right)$. According to Tukey post hoc tests, the natural sentences are read faster than the anomalous sentences with both adjunct $\left(p_{A D J}=0.002\right)$ and argument/instrument $\left(p_{A R G / I N S}=0.009\right)$ phrases.

There were no significant interactions between variables in Turkish. The phrase-normality interaction which was found in English did not exist in Turkish as seen in Figure 2.

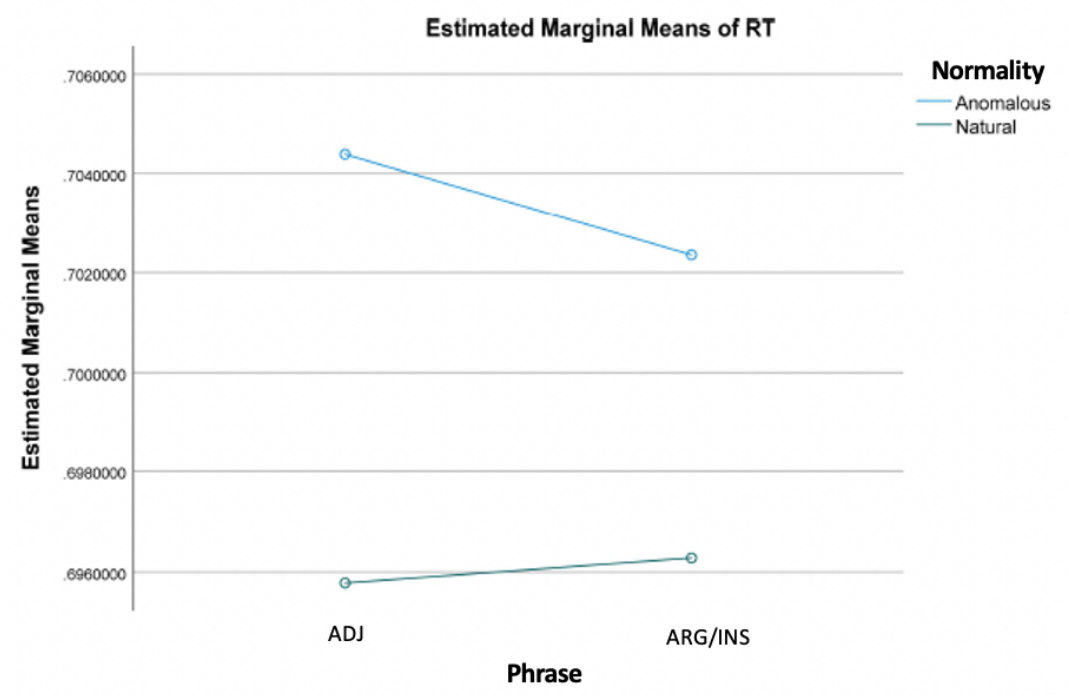

Figure 2: Effect of normality on the RTs of ADJ and ARG/INS phrases in Turkish

This figure shows that sentences that contain adjunct phrases and argument or instrument phrases act similarly. Participants reacted faster to natural sentences and slower to anomalous sentences for both phrase types.

\subsection{Discussion}

As discussed in section 1, the argument-adjunct distinction is highly important for theoretical linguistics and psycholinguistics. This difference is not always easy to make, as there are some unclear cases. One of those cases is instrumental sentences.

According to the self-paced online reaction time study, there was no difference between arguments, adjuncts and instruments in English and in Turkish. This results were unexpected, because in the literature there are eye tracking and response time studies that show a difference between the reading response times of arguments and adjuncts. For example, Clifton et al. (1991), measured local reading times during and after a preposition phrase (PP) that was disambiguated by the plausibility of it being an argument or adjunct. 
The sentence with an argument PP (117a) and with and adjunct PP (117b) had different reading times. The argument PPs were read faster than adjunct PPs.

(117) a. The doctor lectured on heart disease.

b. The doctor lectured on Sunday.

Similarly, Mauner, Tanenhaus and Carleson (1995), Koening and Mauner (2000) found that readers read argument PPs faster than adjunct PPs even when the argument PPs were less plausible (Koenig et al., 2003).

The argumenthood of instruments is especially hard to decide as some linguists argue that instruments are arguments Schutze, 1995; Schutze and Gibson among) others while others argue that they are adjuncts (Spivey, Tanenhaus, Eberhard, Sedivy 2002; Spivey-Knowlton Sedivy 1995 among others). Examining whether unclear cases such as instruments are argument or adjunct is especially important to have a better understanding of the argument-adjunct distinction, because categorizing them as either arguments or adjuncts is harder than phrases that indicate frequency, time or location.

Also, Koenig et al. (2003) tested the distinction between arguments and adjuncts in a reading time experiment. Their results showed that most action verbs do not take instruments as arguments, but a small subset of action verbs do. However, according to the results it is possible to determine the linguistic status of instruments as event participants stored with, and introduced by verbs (Tutunjian and Boland 2005). The event participants are significantly different than linguistic arguments, as linguistic arguments are syntactically obligatory for a target notion while event participants are not (Barbu et. al. 2016).

There are also eye-tracking studies on instruments. For example, Boland (2005) conducted an eye-tracking study to investigate which category instruments fall under. However, the results of the studies were unexpected. Instruments did not fall under either category. They fell between arguments and adjuncts. Boland (2005) argued that instruments got more looks (more fixation) than locations (clear adjuncts) and less looks than recipients (clear arguments). They concluded that these results make instruments neither typical arguments nor adjunct.

In other words, I was expecting to find a difference between clear adjuncts and clear arguments in English, as there are similar experiments showing a difference between those categories. I was also expecting to see that the instruments would fall somewhere in between the arguments and adjuncts, since that is what Boland (2005) found in her eye-tracking study. As Barbu (2020) showed similar results for English and Turkish studies and after running argumenthood tests in both languages and realize that they work similarly in both languages, I expected to see a similar result in Turkish as well.

However, my results did not show any significance between those three groups. There might be several reasons for that. One of them could be that my method was not sensitive enough to capture the differences. It was sensitive enough to capture the differences between the natural and anomalous sentences in Turkish but not between the natural 
sentences in either of the languages.

As mentioned in section 3.1, the study designs of the two languages were identical and the sentences were parallel to each other. However, as mentioned in 3.2, in English there is a significant difference between natural and anomalous sentences for only the sentences containing ADJ phrases but not the ones with ARG/INS phrases. On the other hand, in Turkish both the sentences with ADJ phrases and the sentences with ARG/INS phrases have a significant difference between natural and anomalous sentences. The reason behind this difference between the two languages is worth analyzing.

The second possible reason that there was no significant difference between arguments, adjuncts and instruments is that most of the self-paced reaction time studies are run in-person, whereas I conducted an online study. Even if the software (Pavlovia) that I used was accurate, in online studies it is easier for the participants to get distracted.

The third possible reason is that the participants stopped paying attention and pressed the buttons without reading the sentences. To rule that possible complication out, I erased the wrong answers and the participants with the most wrong answers. However, note that most participants answered according to expectations.

\section{Conclusion}

Instruments are expressed by prepositional phrases such as 'with a knife' in (118) which was discussed in section 1.2. My intuition is not different from the classification in the literature. As discussed in section 1.2, according to Koenig et al. (2003), and Rissman et al. (2015), verbs that can take instruments can be divided into two types: require verbs and allow verbs. They argue that require-instruments are more argument-like and allow-instruments are more adjunct-like. This division also aligns with my intuition on categorizing instrumental phrases. Margie sliced the bread with a knife.

This thesis investigated the argument-adjunct distinction and the classification of instruments. It addresses the argumenthood status of instrumental phrases in three ways.

It discussed whether the instrumental preposition with in English and the instrumental case marking -(y)le in Turkish can also be used to mark clear arguments and clear adjuncts. As mentioned in section 1.2.1 and 1.2.2, they are not specific to instruments. They are neither specific to clear arguments nor clear adjuncts. In other words, they cannot be used to classify the instruments as one or the other.

In section 2, argumenthood tests previously proposed for English were applied to Turkish and also to instruments. Some of those tests classified the instrumental phrases as arguments, some of them classified them as adjuncts and some of them were inconclusive. To summarize, the traditional argumenthood tests were not useful in classifying instruments. 
In my opinion the argumenthood tests give different results while classifying instruments because they pick up different things. In other words, they compare different properties of instrumental phrases. For example, some tests compare semantic properties and some of them compare syntactic properties.

Lastly, self-paced reaction time studies were conducted to investigate the classification of instrumental phrases more in detail. However, as mentioned in section 2.2, according to this test, there was no significant difference between arguments, adjuncts and instruments in neither of the languages. As discussed in section 2.3, there were several reasons for those results, and it is highly possible that the method and the software used for the experiment were not sensitive enough to capture those differences. The expectation was to find differences between groups, as response time (Koenig et al. 2003) and eye tracking (Boland 2005) studies showed significant differences between groups.

In the future, it would be worth comparing arguments, adjuncts and instruments of English and Turkish with an eye-tracking study as eye tracking studies are more sensitive than self-paced reaction time studies. It might also be interesting to compare the natural and anomalous sentences in those languages as this study showed a significant difference between natural and anomalous sentences of arguments and adjuncts in Turkish but not in English. 


\section{Appendix}

\subsection{Appendix 1: English study}

\section{Demographic questionnaire}

Instructions: Please answer the following questions to the best of your knowledge.

1. Please select your age range:

$\square 18-22 \quad \square 23-40 \quad \square 41$ and above

2. What was the primary language spoken in your household during your childhood?

$\square$ English $\quad \square$ French $\quad \square$ others

3. If English is not your first language, please state at what age you started learning English.

$\square 0-8 \quad \square 9-16 \quad \square 17-24 \quad \square 25$ and above

4. Do you self-identify yourself as monolingual?

$\square$ Yes $\quad \square$ No

\section{Study Instructions}

On your screen, you will see sentences containing 5 to 7 words. If you are doing this study on a touch screen, please press the green button for "natural" English sentences, and red button for "anomalous" sentences. If you are doing the study on a computer, please press $\mathrm{N}$ for "natural" English sentences and A for anomalous sentences.

The verbs used in the study are seen in the table 10 .

\begin{tabular}{|c|c|c|}
\hline Require verbs & Allow verbs & Ditransitive verbs \\
\hline To cut & To open & To give \\
\hline To draw & To wash & To sell \\
\hline To paint & To eat & To ask \\
\hline To write & To drink & To bring \\
\hline To slice & To clean & To show \\
\hline To comb & To defend & To deliver \\
\hline
\end{tabular}

Table 10: English verbs by group 


\section{Sentences (Survey A)}

\section{Require verbs}

\section{To cut}

(119) a. Addison Cut the papers with plastic scissors.

b. * Madelyn cut the papers with cold care.

\section{To draw}

(120) a. Kylen drew a picture with colored pens.

b. * Marc drew a picture with sandy dignity.

\section{To paint}

(121) a. Margot painted the wall with a new brush.

b. * Sophia painted the wall with a curly smile.

\section{To write}

(122) a. * Simon wrote the question with a metal chalk.

b. Roy wrote the question with enourmous dignity.

\section{To slice}

(123) a. Liana sliced the vegetables with amazing care.

b. * Olivia sliced the vegetables with a shameless knife.

\section{To comb}

(124) a. Bruce combed his hair with a big smile.

b. * Philip combed his hair with his innocent comb.

\section{Allow verbs}

\section{To open}

(125) a. * Barbara opened the door with slippery pleasure.

b. Warren opened the door with his clean hands. 


\section{To wash}

(126) a. Gabrielle washed her face with parfumed soap.

b. * Aaron washed his face with snowy joy.

\section{To eat}

(127) a. Daniel ate his salad with a new fork.

b. * Christopher ate his salad with square sadness.

\section{To drink}

(128) a. Emma drank her coke with tremendous sadness.

b. * Laura drank his coke with a fast straw.

\section{To clean}

(129) a. Frederick cleaned his room with exceptional joy.

b. * Leo cleaned her room with a sharp broom.

\section{To defend}

(130) a. Julia defended herself with great pleasure.

b. $\quad *$ Rose defended herself with purple words.

\section{Ditransitive verbs}

\section{To give}

(131) a. Oliver gave his bike to Amelia.

b. * George gave his bike tightly.

\section{To sell}

(132) a. Samantha sold her car to James.

b. * Isla sold her car mildly.

\section{To send}

(133) a. Charles sent the card to Linda.

b. * Ava delivered the box a little. 


\section{To bring}

(134) a. Bethany brought the cake happily.

b. * Sophia brought the cake to the lamp.

\section{To show}

(135) a. Joe showed his drawings impatiently.

b. * Damian showed his drawing to the picture.

To deliver

(136) a. Linda delivered the box secretly.

b. * Ava delivered the box to the trash.

\section{Sentences (Survey B)}

\section{Require verbs}

\section{To cut}

(137) a. Addison cut the papers with great care.

b. * Madelyn cut the papers with the tense scissors.

\section{To draw}

(138) a. Kyle drew a picture with enormous dignity.

b. * Marc drew a picture with noisy pens.

\section{To paint}

(139) a. Margot painted the wall with a huge smile.

b. * Sophia painted the wall with a quiet brush.

\section{To write}

(140) a. Roy wrote the question with a white chalk.

b. * Sophia wrote the question with a curly smile. 


\title{
To slice
}

(141) a. Liana sliced the vegetables with a sharp knife.

b. * Olivia sliced the vegetables with ordered care.

\section{To comb}

(142) a. Bruce combed his hair with his hand.

b. * Philip combed his hair with a blue smile.

\begin{abstract}
Allow verbs
To open

(143) a. Warren opened the door with tremendous pleasure.

b. * Barbara opened the door with her modern hand.
\end{abstract}

To wash

(144) a. Gabrielle washed her face with extreme joy.

b. * Aaron washed his face with a metallic soap.

\section{To eat}

(145) a. Daniel ate his salad with great sadness.

b. * Christopher ate his salad with a burnt fork.

\section{To drink}

(146) a. Emma drank her coke with a long straw.

b. * Laura drank her coke with square sadness.

\section{To clean}

(147) a. Frederick cleaned his room with a new broom.

b. * Leo cleaned his room with windy joy.

\section{To defend}

(148) a. Julia defended herself with nice words.

b. * Rose defended herself with blobby pleasure. 


\section{Ditransitive verbs}

\section{To give}

(149) a. Oliver gave his bike voluntarily.

b. * George gave his bike to the tree.

\section{To sell}

(150) a. Samantha sold her car involuntarily.

b. * Isla sold her car to her hand.

\section{To send}

(151) a. Charles sent the card unwillingly.

b. * Thomas sent the card to his pen.

\section{To bring}

(152) a. Bethany brought the cake to William.

b. * Sophia brought the cake weakly.

To show

(153) a. Joe showed his drawings to Emma.

b. * Damian showed his drawing by shivering.

\section{To deliver}

(154) a. Linda delivered the box to Richard.

b. * Ava delivered the box a little. 


\subsection{Appendix 2 : Turkish study}

\section{Demographic questionnaire / Demografik ve dil geçmişi anketi}

Açılamalar: Lütfen aşağıdaki soruları size en uygun şekilde cevaplayınız.

1. Lütfen yaş aralığınızı seçiniz.

$\square 18-22 \quad \square 23-40 \quad \square 41$ ve üzeri

2. Çocukluğunuzda evde başlıca konuşulan dil neydi?

$\square$ Türkçe $\quad \square$ İngilizce $\quad \square$ Diğer diller

3. Eğer anadiliniz Türkçe değilse, kaç yaşında Türkçe öğrendiniz?

$\square 0-8 \quad \square 9-16 \quad \square 17-24 \quad \square 25$ ve üzeri

4. Kendinizi monolingual (tek dil bilen) olarak mı tanımlarsınız?

$\square$ Evet $\square$ Hayır

\section{Study Instructions}

Ekranınızda beş kelimeden oluşan cümleler göreceksiniz. Eğer araştırmayı dokunmatik bir ekrandan yapıyorsanız, "normal" Türkçe cümleler için yeşil "aykırı" cümleler için kırmızı noktaya tıklayınız. Eğer araştırmayı bilgisayarınızdan yapıyorsanız, "normal" Türkçe cümleler için N, "aykırı" cümleler için A tuşuna tıklayınız. Bu sizi bir sonraki cümleye yönlendirecektir.

The verbs used in the study were listed in the table 11.

\begin{tabular}{|c|c|c|}
\hline Require Verbs & Allow Verbs & Ditransitive Verbs \\
\hline Kesmek 'to cut' & Açmak 'to open' & Vermek 'to give' \\
\hline Çizmek 'to draw' & Y1kamak 'to wash' & Satmak 'to sell' \\
\hline Boyamak 'to paint' & Yemek 'to eat' & Sormak 'to ask' \\
\hline Yazmak 'to write' & İçmek 'to drink' & Getirmek 'to bring' \\
\hline Dilimlemek 'to listen' & Temizlemek 'to clean' & Göstermek 'to show' \\
\hline Taramak 'to comb' & Savunmak 'to defend' & Teslim etmek 'to deliver' \\
\hline
\end{tabular}

Table 11: Turkish verbs by group 


\section{Sentences (Survey A)}

\section{Require verbs}

\section{Kesmek - to cut}

(155) a. Jale kağıtları plastik makasla kesti. Jale paper-PL-ACC plastic scissors-INS cut-PAST

'Jale cut the papers with plastic scissors.'

b. * Meral kağıtları geniş özenle kesti. Meral paper-PL-ACC large care-INS cut-PAST 'Meral cut the papers with a large care.'

\section{Çizmek - to draw}

(156) a. Serkan renkli kalemlerle resim çizdi. Serkan colored pen-PL-INS picture draw-PAST

'Serkan drew a picture with colored pens.'

b. * Mete engin bir üzüntüyle resim çizdi. Mete broad one sadness-INS painting draw-PAST

'Mete drew a painting with broad sadness.'

\section{Boyadı - to paint}

(157) a. Özge duvarı yeni firçayla boyadı. Özge wall-ACC new brush-INS paint

'Özge painted the wall with a new brush.'

b. * Nalan duvarı boğan istekle boyadı. Nalan wall-ACC choker desire paint-PAST

'Nalan painted the wall with a choker desire.'

\section{Yazmak - to write}
a. Okan soruyu metal tebeşirle yazdı.
Okan question-ACC metal chalk-INS write-PAST

'Okan wrote the question with a metal chalk.'

b. * İlhan soruyu gereksiz bir sabirla yazdı.

İlhan question-ACC unnecessary one patience write-PAST

'Ilhan wrote the question with an unnecessary patience.' 


\section{Dilimlemek - to slice}

a. Tuba sebzeleri büyük bir hızla dilimledi.

Tuba vegetable-PL-ACC big one fast-INS slice-PAST

'Tube sliced the vegetables really fast.'

b. * Ceren sebzeleri arsı bıçakla dilimledi.

Ceren vegeteble-PL-ACC shamless knife-INS slice-PAST

'Ceren sliced the vegetables with a shamless knife.'

\section{Tamarak - to combe}

(160) a. Meltem saçlarını istekle uzun uzun taradı.

Meltem hair-PL-POSS desire-INS long long comb-PAST

Meltem combed her hair ambitiously for a long time.'

b. * Gülşah saçlarını masum tarağıyla taradı.

Gülşah hair-PL-POSS-ACC innocent comb-POSS-INS comb-PAST

'Gülşah combed her hair with her innocent comb.'

\section{Allow verbs}

\section{Açmak - to open}

(161) a. Tülin kapıyı temiz eliyle açtı.

Tülin door-ACC clean hand-POSS-INS open-PAST

'Tülin opened the door with her clean hand.'

b. * Elif kapıyı derin bir hışımla açtı.

Elif door-ACC deep one anger-INS open-PAST

'Elif opened the door with a deep anger.'

\section{Ylkamak - to wash}

(162) a. Ulaş yüzünü kokulu sabunla yıkadı.

Ulaş face-ACC perfumed soap wash-PAST.

'Ulaş washed his face with parfumed soap.'

b. * Barış yüzünü biraz mutlulukla yıkadı.

Barış face-POSS-ACC a-little happiness wash-PAST

'Barış washed his face with a little happiness.' 


\section{Yemek - to eat}

(163) a. Fulya salatasını yeni çatalıyla yedi.

Fulya salad-POSS-ACC new fork-INS eat-PAST

'Fulya ate her salad with a new fork.'

b. * Yeşim salatasını engin bir telaşla yedi.

Yeşim salad-POSS-ACC broad one hurry eat-PAST

'Yeşim ate her salad in a broad hurry.'

\section{İçmek - to drink}

(164) a. Taner kolasını saçma bir keyifle içti.

Taner coke-POSS-ACC absurd one pleasure drink-PAST

'Taner drank his coke with an absurd pleasure.'

b. * Yılmaz kolasını hızlı kamışıla içti.

Yilmaz coke-POSS-ACC fast straw-INS drink-PAST

'Yılmaz drank his coke with a fast straw.'

\section{Temizlemek - to clean}

(165) a. Dilek odasını büyük bir dikkatle temizledi.

Dilek room-POSS-ACC big care-INS clean-PAST

'Dilek cleaned her room carefully.'

b. * Seçil odasını keskin süpürgesiyle temizledi. Seçil room-POSS-ACC sharp broom-POSS-INS clean-PAST

'Seçil cleaned her room with a sharp broom.'

\section{Savunmak - to defend}

(166) a. Tekin kendini büyük samimiyetle savundu.

Tekin himself big honest-INS defend-PAST

'Tekin defended himself honestly.'

b. * Cihan kendini gizli sözlerle savundu. Cihan himself private word-PL-INS defend-PAST

'Cihan defended himself with private words.' 


\section{Ditransitive verbs}

\section{Vermek - to give}

(167) a. Bülent bisikletini Reyhan'a verdi.

Bülent bike-POSS-ACC Reyhan-DAT give-PAST

'Bülent gave his bike to Reyhan.'

b. * Soner bisikletini oldukça verdi.

Soner bike-POSS-ACC quite give-PAST

'Soner quite gave his bike.'

\section{Satmak - to sell}
a. Beren arabasını Yavuz'a sattı.
Beren car-POSS-ACC Yavuz-DAT sell-PAST
'Beren sold her car to Yavuz.'
b. * Seçil arabasını fazla sattı.
Seçil car-POSS-ACC much sell-PAST
'Seçil sold much her car.'

\section{Sormak - to ask}

(169) a. Çınar Gamze'ye adres sordu.

Çınar Gamze-DAT address ask-PAST

'Çınar asked the address to Gamze.'

b. * Tolga uyuyarak adres sordu.

Tolga by-sleeping address ask-PAST

'Tolga asked the address by sleeping.'

\section{Getirmek - to bring}

(170) a. Özge sakince pasta getirdi.

Özge calmly cake bring-PAST

'Özge brought the cake calmly.'

b. * Dicle lambaya pasta getirdi.

Dicle lamp-DAT cake bring-PAST

'Dicle brought the cake to the lamp.' 


\section{Göstermek - to show}

a. Pamir sabırsızca çizimlerini gösterdi.

Pamir impatiently drawing-PL-POSS-ACC show-PAST

'Pamir showed his drawings impatiently.'

b. * Ömer tabloya çizimlerini gösterdi.

Ömer painting-DAT drawing-PL-POSS-ACC show-PAST

'Ömer showed the picture to his drawings.'

\section{Teslim etmek - to deliver}
a. Prrl kutuyu gizlice teslim etti.
Pirıl box-ACC secretly deliver-PAST
'Prrll delivered the box secretly.'
b. * Sanem kutuyu çöpe teslim etti. Sanem box-ACC trash-ACC deliver-PAST
'Sanem delivered the box to the trash.'

\section{Sentences (Survey B)}

\section{Require verbs}

\section{Kesmek - to cut}
a. Jale kağıtları büyük özenle kesti.
Jale paper-PL-ACC big care-INS cut-PAST
'Jale cut the papers with a lot of care.'
b. * Meral kağıtları gergin makasla kesti. Meral paper-PL-ACC tense scissors-INS cut-PAST
'Meral cut the papers with tense scissors.'

\section{Çizmek - to draw}

(174) a. Serkan derin bir üzüntüyle resim çizdi.

Serkan deep one sadness-INS painting draw-PAST

'Serkan drew a painting sadly.'

b. * Mete gürültülü kalemlerle resim çizdi.

Mete noisy pen-PL-INS picture draw-PAST

'Mete drew a picture with noisy pens.' 


\section{Boyamak - to paint}

(175) a. Özge duvarı inanılmaz bir istekle boyadı.

Özge wall-ACC unbelievable one desire-INS paint-PAST

'Özge painted the wall with an unbelievable desire.'

b. * Nalan duvarı sessiz firçayla boyadı.

Nalan wall-ACC quiet brush-INS paint-PAST

'Nalan painted the wall with a quiet brush.'

\section{Yazmak - to write}
a. İlhan soruyu beyaz tebeşirle yazdi.
İlhan question-ACC white chalk-INS write-PAST

'İlhan wrote the question with a white chalk.'
b. * Okan soruyu biraz sabırla yazdı. Okan question-ACC a-little patience write-PAST

'Okan wrote the question with a little patience.'

\section{Dilimlemek - to slice}

(177) a. Tuba sebzeleri keskin bıçakla dilimledi. Tuba vegetable-PL sharp knife-INS slice-PAST

'Tuba sliced the vegetables with a sharp knife.'

b. * Ceren sebzeleri derin bir hizla dilimledi. Ceren vegeteble-PL deep one speed-INS slice-PAST

'Ceren sliced the vegetables with a deep speed.'

\section{Taramak - to comb}
a. Meltem saçlarını
yeni tarağıyla taradı.
Meltem hair-PL-POSS-ACC new comb-POSS comb-PAST
'Meltem combed her hairs with her new comb.'
b. * Gülşah saçlarını hızlı bir istekle taradı.
Gülşah hair-PL-POSS-ACC fast one desire comb
'Gülşah combed her hair with a fasr desire.'



Allow verbs
Açmak - to open
(179) a. Tülin kapıyı saçma bir hışımla açtı.
Tülin door-ACC wierd one anger-INS open-PAST
'Tülin opened the door with a wierd anger.'
b. * Elif kapıyı eski eliyle açtı.
Elif door-ACC ancient hand-INS open-PAST
'Elif opened the door with her ancient hand.'

\section{Yıkamak - to wash}
a. Ulaş yüzünü
büyük mutlulukla yıkadi.
Ulaş face-POSS-ACC big happiness-INS wash-PAST
'Ulaş washed his face very happily.'
b. * Barış yüzünü modern sabunla yıkadı.
Barış face-POSS-ACC modern soap-INS wash-PAST
'Barış washed his face with a modern soap.'

\section{Yemek - to eat}
a. Fulya salatasını ciddi bir telaşla yedi.

Fulya salad-POSS-ACC serious one hurry-INS eat-PAST

'Fulya ate her salad in a hurry.'
b. * Yeşim salatasını yanık çatalıyla yedi.
Yeşim salad-POSS-ACC burnt fork-POSS-INS eat-PAST
'Yeşim ate her salad with her burnt fork.'

\section{İçmek - to drink}

(182) a. Taner kolasını uzun kamışıyla içti. Taner coke-POSS-ACC long straw-POSS-INS drink-PAST

'Taner drank his coke with his long straw.'

b. * Yılmaz kolasını boğan bir keyifle içti. Yilmaz coke-POSS-ACC choking one pleasure drink-PAST

'Yılmaz drank his coke with a choking pleasure.' 


\section{Temizlemek - to clean}

a. Dilek odasını el süpürgesiyle temizledi.

Dilek room-POSS-ACC hand broom-INS clean-PAST

'Dilek cleaned her room with a hand broom.'

b. * Seçil odasını fazla dikkatle temizledi.

Seçil room-POSS-ACC much care-INS clean-PAST

'Seçil cleaned her room with a lot of care.'

\section{Savunmak - to defend}
a. Tekin kendini kırıcı sözlerle savundu. Tekin himself offending word-PL-INS defend-PAST
'Tekin defended himself with offending words.'
b. * Cihan kendini çok samimiyetle savundu.
Cihan himself much honest-INS defend-PAST
'Cihan defended himself much honestly.'

\section{Ditransitive verbs}

\section{Vermek - to give}

(185) a. Bülent bisikletini bisikletini mecburen verdi.

Bülent bike-POSS-ACC compulsory give-PAST

'Bülent gave his bike compulsory.'

b. * Soner bisikletini ağaca verdi.

Soner bike-POSS-ACC tree-DAT give-PAST

'Soner gave his bike to the tree.'

\section{Satmak - to sell}

(186) a. Beren arabasını istemeden satt1. Beren car-POSS-ACC involuntarily sell-PAST

'Beren sold her car involuntarily.'

b. * Seçil arabasını eline sattı. Seçil car-POSS-ACC hand-POSS-DAT sell-PAST

'Seçil sold her car to her hand.' 


\section{Sormak - to ask}

(187) a. Çınar isteksizce adres sordu.

Çınar unwillingly address ask-PAST

'Çınar asked the address unwillingly.'

b. * Tolga kalemine adres sordu.

Tolga pen-POSS-DAT address ask-PAST

'Tolga asked the address to his pen.'

\section{Getirmek - to bring}

(188) a. Özge Serdar'a pasta getirdi.

Özge Serdar-DAT cake bring-PAST

'Özge brought cake to Serdar.'

b. * Dicle asla pasta getirdi.

Dicle never cake bring-PAST

'Dicle never brought cake.'

\section{Göstermek - to show}

a. Pamir Sanem'e çizimlerini gösterdi.

Pamir Sanem-DAT drawing-PL-POSS-ACC show-PAST

'Pamir showed Sanem his drawings.'

b. * Ömer parçalayarak çizimlerini gösterdi.

Ömer by-shivering drawing-PL-POSS-ACC show-PAST

'Ömer showed drawings by shivering.'

\section{Teslim etmek - to deliver}

(190) a. Prrl kutuyu İsmail'e teslim etti.

Pırıl box-ACC İsmail-DAT deliver-PAST

'Prrll delivered the box to İsmail.'

b. * Sanem kutuyu biraz teslim etti.

Sanem box-ACC a-little deliver-PAST

'Sanem delivered the box a little.' 


\section{References}

Abney, S. P. (1989). A computational model of human parsing. Journal of Psycholinguistic Research, 18(1), 129-144.

Ackema, P. (2015). Arguments and adjuncts. In Handbücher zur Sprach-und Kommunikationswissenschaft/Handbooks of Linguistics and Communication Science (HSK) 42/1 246-274. De Gruyter Mouton.

Barbu, R. M., Toivonen, I. (2016). Arguments and adjuncts: at the syntax-semantics interface. Florida Linguistics, $3(1)$.

Barbu, R. M. (2020). On the psycholinguistics of argumenthood. [Unpublished doctoral dissertation.] Carleton University.

Bierwisch, M. (2011). The event structure of cause and become. In C. Maienborn A. Wöllstein (Eds.) Event arguments: foundations and applications 11-44. Max Niemeyer Verlag.

Bresnan, J. (ed.) (1982). The mental representation of grammatical relations. Cambridge, MA: MIT Press, 173-281.

Bresnan, J. (1982). Control and complementation. Linguistic Inquiry, 13(3), 343-434.

Boland, J. E. (2005). Visual arguments. Cognition, 95(3), 237-274.

Carnie, A. (2012). Syntax: A generative introduction (Vol. 18). Oxford: Blackwell Publishing.

Chametzky, R. A. (2003). Phrase structure, in R. Hendrick (ed.) Minimalist syntax, Oxford: Blackwell, 192-225.

Chambers, C. G., Tanenhaus, M. K., \& Magnuson, J. S. (2004). Actions and affordances in syntactic ambiguity resolution. Journal of Experimental Psychology: Learning, Memory, and Cognition, 30(3), 687.

Chomsky, N. (1981). Lectures on government and binding. Dordrecht, The Netherlands: Foris.

Croft, William. (1991). Syntactic categories and grammatical relations: The cognitive organization of information. Chicago: University of Chicago Press

Culicover, Peter W. (1997). Principles and parameters: An introduction to syntactic theory. New York: Oxford University Press.

Cuyckens, H. \& Geeraerts D. (Eds.) (2007). Cognitive linguistics. Oxford University Press.

DeArmond, R. C., \& Hedberg, N. (1998). On complements and adjuncts. In Proceedings of the Canadian Linguistics Society Meeting, Cahiers linguistiques d'Ottawa 95-106.

Gračanin Yuksek, M. (2007). About sharing [Unpublished doctoral dissertation.] Massachusetts Institute of Technology.

Grimshaw, J., \& Vikner, S. (1993). Obligatory adjuncts and the structure of events. In E. Reuland \& W. Abraham (Eds.) Knowledge and language: Lexical and Conceptual Structure (pp. 143-155). Dordrecht: Kluwer Academic Publisher.

Haegeman, Liliane. (1994). Introduction to government and binding theory. Oxford: Blackwell.

Hedberg, N., \& DeArmond, R. C. (2009). On complements and adjuncts. Snippets, 19, 11-12. 
Hengirmen, M. (1997). Türkçe dilbilgisi. Engin.

İşsever, S. (2009). A syntactic account of wh-in-situ in Turkish. Essays on Turkish linguistics.

Wiesbaden: Harrasowitz Verlag, 103-112.

Jackendoff, R. (1977). X-bar syntax: A study of phrase structure. Cambridge, MA: MIT Press.

Jackendoff, R. (2002). English particle constructions, the lexicon, and the autonomy of syntax. In Déhe et al. (Eds.), 67-94.

Kaplan, R. M., Bresnan, J. Lexical-Functional Grammar: A formal system for grammatical representation.

In Bresnan, J. (Ed.), The mental representation of grammatical relations (pp. 173-281). Cambridge, MA: MIT Press.

Kearns, K. (2011). Semantics. Palgrave Modern Linguistics.

Knecht, L. (1986). Lexical causatives in Turkish. In Slobin, D. \& Zimmer, K. (Eds.), Studies in Turkish Linguistics. Amsterdam: John Benjamins.

Konieczny, L., Hemforth, B., Scheepers, C., \& Strube, G. (1997). The role of lexical heads in parsing: Evidence from German. Language and Cognitive Processes, 12(2-3), 307-348.

Koenig, J. P., Mauner, G. \& Bienvenue, B. (2003). Arguments for adjuncts. Cognition, 89(2):67-103.

Koenig, J. P., Mauner, G., Bienvenue, B., \& Conklin, K. (2008). What with? the anatomy of a (proto)-role. Journal of Semantics, 25(2):175-220.

Kornfilt, J. (2013). Turkish. Routledge.

Kroeger, Paul R. (2004). Analyzing syntax: A lexical-functional approach. Cambridge: Cambridge University Press.

Lasnik, H. (1988). Subjects and the $\theta$-criterion. Natural Language Linguistic Theory, 6(1), 1-17.

Lakoff, G., \& Ross, J. R. (1976). Why you can't do so into the sink. In J. McCawley (Ed.) Notes from the linguistic underground (pp. 101-111). Brill.

Lyons, J. (1968). Existence, location, possession and transitivity. In B. Van Rootselaar J.F. Staal (Eds.) Studies in Logic and the Foundations of Mathematics (Vol. 52, pp. 495-504). Elsevier.

Melchin, P. B., \& Toivonen, I. (2018). Wh-word conjunction as a test for argumenthood and obligatoriness. Proceedings of the Linguistic Society of America, 3(1), 15-1.

Needham, S. \& Toivonen, I. (2011). Derived arguments. In Butt, M \& King, T. H. (Eds.) Proceedings of the LFG11 Conference (pp. 401-421). Stanford: CSLI.

Ono, N. 1992. Instruments: a case study of the interface between syntax and lexical semantics. English Linguistics, 9, 196-222.

Radford, Andrew. (2004). Minimalist syntax: Exploring the structure of English. Cambridge, UK: Cambridge University Press.

Rissman, L., \& Rawlins, K. (2017). Ingredients of instrumental meaning. Journal of Semantics, 34(3), 507-537. 
Rissman, L. (2011). Instrumental with and use: Modality and implicature. In Semantics and Linguistic Theory (Vol. 21, pp. 532-551).

Sedivy, J., \& Spivey-Knowlton, M. (1994). The use of structural, lexical, and pragmatic information in parsing attachment ambiguities. In C. Clifton, Jr., L. Frazier, \& K. Rayner (Eds.), Perspectives on sentence processing (pp. 389-413). Lawrence Erlbaum Associates, Inc.

Schütze, C. T. (1999). English expletive constructions are not infected. Linguistic Inquiry, 30(3), 467-484.

Tallerman, Maggie. (2005). Understanding syntax, 2nd edition. London: Hodder Arnold.

Tesnière, L (1959). Eléments de syntaxe structurale. Librarie C. Klicksieck.

Toivonen, I. (2013). English benefactive NPs. In M. Butt \& T. H. King (Eds.) Proceedings of the LFG 2013 conference (pp. 503-523).

Traxler, M. J. (2011). Introduction to psycholinguistics: Understanding language science. Wiley.

Turan, Ümit D. (1997). Metin işaret adılları: Bu, şu ve metin yapısı (Discourse Deictic pronouns this, that, and the structure of discourse). In XI. Dilbilim Kurultayı Bildiriler (The Proceedings of the XI. Linguistics Conference) (D. Zeyrek Ş Ruhi (eds.)) 22-23 May 1997. Ankara: Middle East Technical University. (pp. 201-212).

Tutunjian, D., \& Boland, J. E. (2008). Do we need a distinction between arguments and adjuncts? Evidence from psycholinguistic studies of comprehension. Language and Linguistics Compass, 2(4), 631-646.

Yamashita, H. (1995). Verb argument information used in a pro-drop language: An experimental study in Japanese. Journal of Psycholinguistic Research 24(5), 333-347.

Van Luven, K. (2014). The argument status of directional PPs. [Undergraduate honors thesis.] Carleton University.

Van Valin, R., and R. Lapolla. (1997). Syntax: form, meaning, and function. Cambridge, MA: Cambridge University Press. 